\title{
Governance implications of modularity in sourcing relationships
}

\author{
Nukhet Harmancioglu ${ }^{1} \cdot$ Stefan Wuyts ${ }^{2} \cdot$ Peren Ozturan $^{3}$ \\ Received: 19 April 2018 / Accepted: 27 September 2020 / Published online: 16 November 2020 \\ (C) Academy of Marketing Science 2020
}

\begin{abstract}
Modularization, an important trend in innovation markets, allows for recombination of product components into multiple end-product configurations. Although modularization has consequences for how firms manage their relationships with upstream component suppliers, the governance implications of modularity for innovation sourcing relationships have not been adequately examined in the prior literature. We intend to bridge this gap. We argue that (i) buyer firms employ governance mechanisms (monitoring and socialization) to cope with the strategic hazards of innovation sourcing relationships (knowledge specificity, knowledge asymmetry, and knowledge spillover) and (ii) the consequences of deploying these mechanisms in response to the strategic hazards on relationship performance are contingent upon the degree of modularity of the system in which they are deployed. We provide empirical support for the developed moderated mediation model through an analysis of 194 innovation projects. The developed theory and findings contribute to the governance and modularity literatures. In addition, our findings may help change managers' behaviors: we observe that managers do not consider modularity when selecting governance mechanisms, while our model findings suggest they should.
\end{abstract}

Keywords Modularity · Organizational control $\cdot$ Innovation sourcing $\cdot$ Moderated mediation

Firms increasingly resort to external sourcing of components to innovate cost-effectively while retaining strategic flexibility (Carson 2007; West and Bogers 2014). The phenomenon of buyer-supplier cooperation for product innovation is prevalent across a spectrum of mostly technology-intensive industries, including consumer-electronics, computer software, automobiles, and pharmaceuticals (Choudhury and Sabherwal 2003; Wang et al. 2008). In recent years, major players such as IBM Corp., Accenture Ltd., Electronic Data Systems Corp., Computer Sciences Corp. and HP Co. have signed mega sourcing contracts nearing $\$ 15$ billion in value (ISG Outsourcing Index). The Boeing Commercial Aircraft Group's Produce Macro-Process Team and

Neil Morgan served as Area Editor for this article.

Nukhet Harmancioglu

nharmancioglu@ku.edu.tr

Stefan Wuyts

suw282@psu.edu

Peren Ozturan

peren.ozturan@ ozyegin.edu.tr

Koç University, Istanbul, Turkey

2 Pennsylvania State University, State College, PA, USA

3 Ozyegin University, Istanbul, Turkey
Sun Microsystems's JAVA development teams are indicative of the trend to seize strategic opportunities via sourcing relationships.

The trend to collaborate with component suppliers goes hand in hand with another trend, to utilize modular product architectures as the basis for innovation design (Ghosh et al. 2006; Parmigiani and Mitchell 2009). Schilling (2000) defines modularity as "a continuum describing the degree to which a system's components can be separated and recombined, and the extent to which the system architecture enables the mixing and matching of components" (p. 312). What enables firms to utilize modular systems, is the presence of industry-wide standards (c.f., Sanchez 1995; Schilling 2000). ${ }^{1}$ Beyond reliance on standardized interfaces between functional components,

\footnotetext{
${ }^{1}$ Once this industry precondition is fulfilled, firms have the managerial discretion to use either modular or integrated systems. For long, companies like Apple have been strategically outsourcing their production to companies such as SCI and other contract manufacturers in order to reduce Apple's manufacturing overhead and inventory carrying costs while concentrating resources more intensively on product design and marketing (Electronics Buyers News, 1996). The customers of SCI included not only Apple, but also more than 50 firms including Hewlett Packard and IBM, companies that compete directly with Apple in the personal computer market. Likewise, the use of modular product architectures in manufacturing has shifted industries from supply on consignment basis to widespread automation of manufacturing processes. This shift was initially observed in electronics manufacturing, but later became prevalent in many of industries such as apparel and footwear, toys, data processing, offshore oil drilling, home furnishings and lighting, semiconductor fabrication, food processing, automotive parts, brewing, enterprise networking, and pharmaceutical production.
} 
modular systems are also characterized by greater reusability and substitutability of component variations into the product architecture without requiring changes in the design of other components (Katz and Shapiro 1994; Sanchez 1999; Schilling 2000). As a result, modularity has been associated with various benefits including product variety and increased efficiency (in terms of time and other resources) in bringing new product innovations to the market. Classic examples include the Sony Walkman and HandyCam, IBM software design modules, Black \& Decker power tools, Boeing and Airbus' use of common wing, nose, and tail components in families of aircraft, and Ford's modular V-8 engine designs (Sanchez 1995; Utterback 1994).

The cooccurrence of the trends toward external sourcing and modularization poses an interesting governance challenge. The external sourcing of components in technologyintensive industries exposes firms to strategic hazards related to development of supplier-specific knowledge (Heide et al. 2007; Mayer and Salomon 2006), knowledge asymmetry (Heide and John 1990; Kirmani and Rao 2000), and knowledge spillover (Frazier et al. 2009; Grant 1996). Knowledge specificity results from proprietary investments in a specific relationship that cannot be redeployed in another relationship. Knowledge asymmetry reflects the lack of familiarity with externally sourced knowledge and/or supplier capabilities. Knowledge leakage refers to the unintended knowledge transfer from the buyer firm to other industry participants, through interactions with the supplier firm.

Our study is based on two key assertions. First, these strategic hazards can turn into strategic opportunities, if properly managed. Second, the effectiveness of governance mechanisms to cope with these strategic hazards depends on the modularity of the system in which they are deployed. Modularity reduces task interdependence ${ }^{2}$ among suppliers of system components, allows for clearer task division and more autonomous task completion, and reduces the cost of switching suppliers (Schilling 2000; Wilson et al. 1990). We argue that these differences between modular and integrative systems have important implications for the governance of supply relationships.

Modularity research has largely ignored the issue of governance. The few studies that did consider it, offer conflicting views (Howard and Squire 2007). Some have argued that modular systems facilitate collaboration between the buyer and component suppliers and enable coordination of loosely coupled geographically dispersed suppliers (Wilson et al. 1990). Others have suggested that the reduced cost of replacing one supplier for another undermines collaboration with

\footnotetext{
${ }^{2}$ We focus on (operational) task interdependence. We do not associate modularity with relational, economic, or technological dependence, which are likely driven by other factors including firm size, market power, market structure, and knowledge dispersion in the industry.
}

suppliers (Schilling 2000; Tiwana 2008). So far, however, a systematic study of the governance implications of system modularity is missing.

We draw on knowledge-accessing theory of interorganizational relationships (Grant and Baden-Fuller 2004) and transaction cost economics (Heide et al. 2007; Williamson 1991) to conceptualize the three strategic hazards associated with external sourcing, namely knowledge specificity, knowledge asymmetry, and knowledge spillover. The governance literature has identified two governance mechanisms that firms employ to address these hazards in technology-intensive industries: monitoring and socialization (Wathne and Heide 2000). Monitoring refers to formal, buyer-initiated mechanisms to incentivize the supplier to behave in line with the stated project objectives (Celly and Frazier 1996; Ouchi 1979). Socialization refers to informal mechanisms, initiated by both or either party to establish goal congruity and minimize divergence of preferences (Eisenhardt 1985; Jaworski 1988). We argue that the effectiveness of monitoring and socialization in addressing strategic hazards varies with the degree of modularity of the system in which they are deployed.

We offer three theoretical contributions. First, we show that when governed properly, knowledge specificity, knowledge asymmetry, and knowledge spillover - traditionally considered to be strategic hazards - all have the potential to boost relationship performance. Second, we contribute to the limited governance literature that has considered contextual variables in the study of efficient alignment of governance mechanisms with strategic hazards (Kim et al. 2011; Mooi and Ghosh 2010). A cross-disciplinary review (see Table 1 ) shows a nearly exclusive focus on environmental and relational contextual factors. We offer an alternative (system) perspective which constitutes a unique contribution to the governance literature: the effectiveness of monitoring and socialization in response to strategic hazards in supply relationships depends on the system's architecture - in particular, its modularity. Third, laying out the entire process, we simultaneously model the impact of strategic hazards on the selection of governance mechanisms and the subsequent impact of governance mechanisms on relationship performance. We specify that this process is moderated by system modularity. We thus estimate the indirect effects of strategic hazards on relationship performance via governance mechanisms, under different modularity conditions.

An empirical test among 194 firms in technology intensive industries (biotechnology, computer hardware and software, telecommunications, pharmaceutical and automotive) provides strong support for the developed theory. The findings reveal a remarkable degree of contrast, as all strategic hazards carry both the threat of reduced relationship performance as well as the opportunity for enhanced relationship performance, dependent on the degree of system modularity. We provide a roadmap indicating which governance mechanisms 


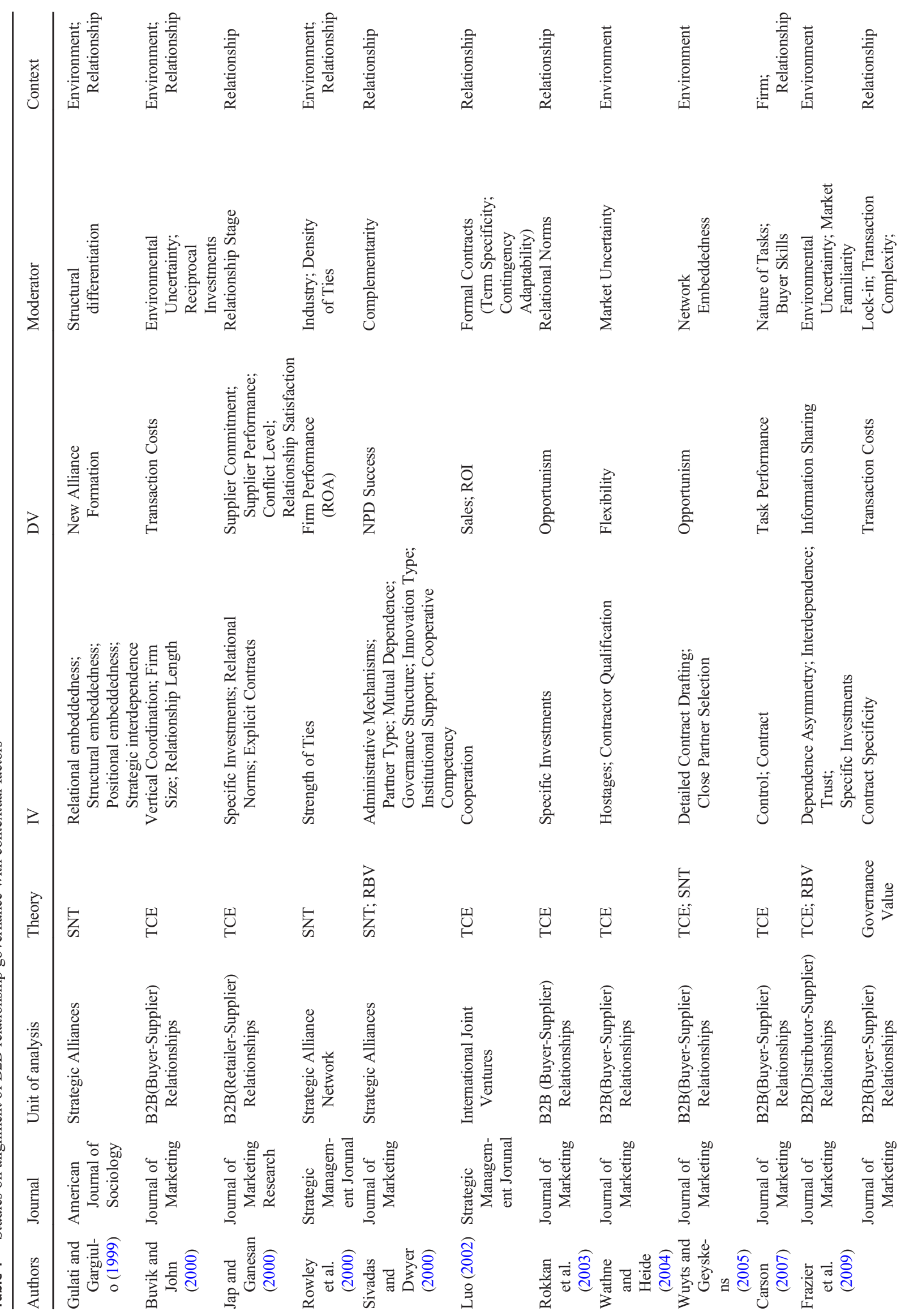




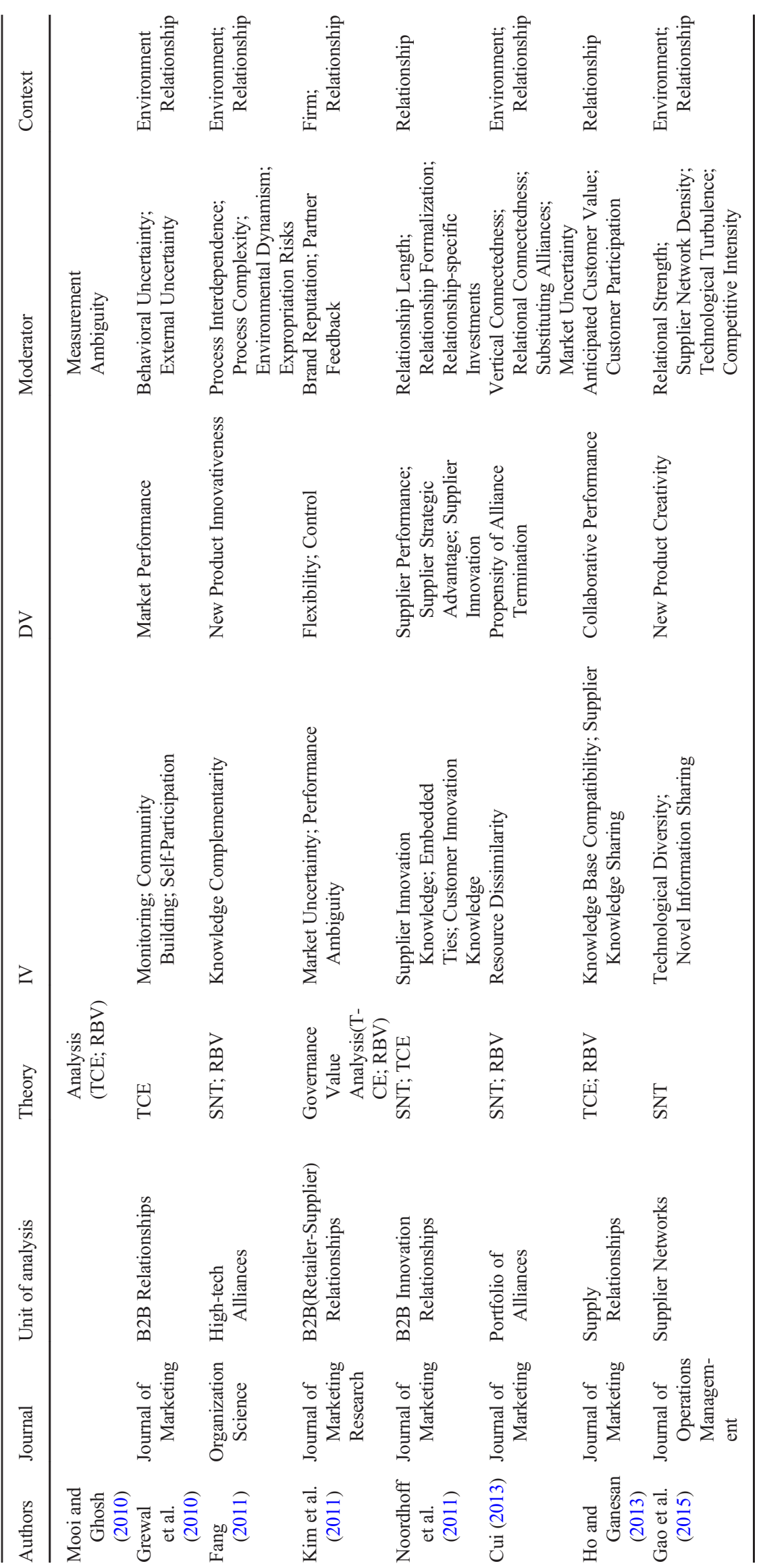


buyers should select as a function of both strategic hazards and system modularity. Interestingly, our findings indicate that managers do not behave optimally as system modularity does not appear to influence their governance choices. Hence, our study may serve to change the way managers govern sourcing relationships in industrial markets.

We commence with an overview of strategic hazards and explain the role of governance mechanisms and modularity in innovation sourcing relationships. Then we develop hypotheses for different components of the conceptual model, building up to moderated mediation effects. After presenting the results, we discuss theoretical and managerial implications.

\section{Conceptual background}

In this section, we outline the different components of our conceptual framework. The outcome variable of interest is relationship performance, which encompasses the firm's general assessment of benefits and returns accruing from the relationship (Griffith et al. 2017) as well as its broader strategic consequences for the firm's financial performance and competitive position (Palmatier et al. 2007). We opt for a performance measure that extends beyond the individual project for two reasons. First, the consequences of bright sides (opportunities) and dark sides (hazards) of knowledge specificity, asymmetry, and spillover may extend beyond the individual innovation project. For example, when knowledge is imperfectly appropriable, knowledge leakage may affect the firm's competitive position. Likewise, if knowledge specificity signals commitment to the relationship, it may stimulate future collaboration on new projects. Second, also the effects of governance mechanisms may go beyond the individual project. $^{3}$ As an example of such second-order effects, Wathne and Heide (2000) suggest that monitoring and socialization lead to self-selection of benevolent future exchange partners. Below, we introduce the three hazards and discuss why they may turn into opportunities; then we discuss monitoring and socialization; we end with the key contingency variable of this study, i.e., system modularity.

\section{Strategic hazards versus strategic opportunities}

As pointed out above, we derive three strategic hazards based on the past literature in interorganizational relationships. First, knowledge specificity (Heide et al. 2007; Mayer and Salomon 2006) creates a problem of moral hazard, due to the proprietary knowledge investments in a specific relationship. Second, knowledge asymmetry (e.g., Heide and John 1990; Stump and

\footnotetext{
${ }^{3}$ Prior marketing research has taken this even one step further and examined the impact of governance mechanisms on firm financial performance (e.g., Raassens et al. 2012)
}

Heide 1996) creates a performance evaluation problem due to the lack of familiarity with supplier capabilities. Third, Grant (1996) pointed out that "knowledge is generally inappropriable by means of market transactions". The spillover hazard, the difficulty for the owner of knowledge to retain the value of knowledge assets, may result in unintended knowledge leakage to other industry participants (Frazier et al. 2009; Grant 1996).

Whereas transaction cost economics traditionally focuses on the risk aspects related to specific investments, asymmetry, and weak appropriability regimes, knowledge-accessing theory (Grant and Baden-Fuller 2004; Mayer and Salomon 2006) suggests that each of these hazards can turn into strategic opportunities. Knowledge specificity can signal commitment to the exchange partner and trigger reciprocal investments, a positive side that has received some attention from transaction cost scholars (see Anderson and Weitz's (1992) argument that connects pledges with commitment). Knowledge asymmetry may indicate specialization. As supplier firms become increasingly specialized, buyer firms are likely to become increasingly unfamiliar with supplier capabilities and tasks (Weiss and Heide 1993). From a knowledge-accessing perspective, it is the uniqueness of the supplier's knowledge that makes collaboration beneficial as collaborating with a specialized supplier expands the buyer's accessible knowledge base (Wu et al. 2015). Finally, knowledge spillover, often associated with unintended leakage, may in fact boost relationship performance as it may offer opportunities for knowledge integration and recombination across firm boundaries, known drivers of innovation (Frazier et al. 2009; Stremersch et al. 2003).

\section{Governance mechanisms}

In interorganizational relationships, firms deploy governance mechanisms to cope with strategic hazards and control their partners' behaviors. Governance mechanisms are employed by a controller (i.e., the buyer) to govern the behavior of a controllee (i.e., the supplier), and to ensure that the controllee acts in a manner consistent with the controller's desired goals (Choudhury and Sabherwal 2003; Eisenhardt 1985; Ouchi 1979). Based on an extensive review of the governance literature, Wathne and Heide (2000) identify four core governance mechanisms: monitoring, incentives, selection, and socialization. They argue that contractually specified incentives and ex ante partner selection are likely to be ineffective in volatile environments. Contractually specified incentive schemes require predictability and are less effective in case of technical change (Wathne and Heide 2000, p. 45). Ex ante partner selection is also less effective as circumstances change, since it relies on the availability of clear pre-specified selection criteria (Wathne and Heide 2000, p. 46). Previous research has consistently pointed to the limited role of these "ex ante" governance mechanisms to hedge against strategic hazards, 
underscoring the need for ex post governance mechanisms (Carson 2007; Ghosh et al. 2006; Mooi and Ghosh 2010). Hence, we focus on the two key ex post governance mechanisms which may help align goals, values, and norms in sourcing relationships: monitoring and socialization. We now turn to a discussion of these mechanisms.

Monitoring includes output and behavior monitoring, which differ based on the degree of supervision, objectivity of evaluation procedures, and time window (Oliver and Anderson 1994). Output monitoring is focused on the realized outputs of the innovation project (project goals, performance standards, functional specifications, target implementation date); suppliers are rewarded for meeting these goals. In behavior monitoring, the buyer monitors the process or means of goal achievement via prescribed rules and procedures (regarding development methodology, weekly progress reports, conference calls) and close observation of the suppliers' behaviors; suppliers are rewarded for following stated procedures (Eisenhardt 1985; Jaworski 1988). While monitoring has distinct advantages, such as shifting project risk to the supplier and penalizing defiant suppliers (Bergen et al. 1992), it may also backfire and promote rather than suppress opportunism (e.g., Deci et al. 1999).

Socialization is an alternative tactic to promote goal convergence and protect firms from vulnerability to opportunistic exploitation (Wathne and Heide 2000). Central to socialization is the process of internalizing the other party's goals and values (Heide and Wathne 2006). In sourcing relationships, socialization often occurs via interactions in project team meetings, which offer opportunities to discuss and internalize the team's goals, values, and norms. Uzzi (1996) found that the extent to which exchange is socially embedded promotes economies of time, as decisions can be made on the fly and less time must be invested in drafting detailed contracts and (re)negotiating the terms of exchange. Yet, such efficiency advantages may not always materialize. In systems where coordination meetings are formalized, goal alignment is more likely and efforts at socialization may be redundant.

\section{Benefits of system modularity}

The deployment of governance mechanisms in response to strategic hazards likely influences relationship performance. Our central argument is that these effects are moderated by system modularity. Systems are said to have a high degree of modularity when component interfaces conform to industrywide standards, allowing the components to be disaggregated and recombined into new configurations with little loss of functionality (Ethiraj and Levinthal 2004; Katz and Shapiro 1994; Schilling 2000). The low task interdependence across a modular system's components has two major benefits for the governance of supplier relationships (Hoetker 2006; John et al. 1999; Sanchez 1995). First, modularity allows for better task division and more autonomous task completion (Schilling 2000; Wilson et al. 1990). For example, Chrysler decomposes its new car platforms into smaller subsystems separated by interfaces (Holmes 1995). Since the development activities can proceed independently across firms, the buyer firm can shift its focus from specifying technical design plans for individual components to specifying the interfaces (Hoetker 2006). John et al. (1999) called this step from monolithic products to decomposable systems a "fundamentally significant transformation" (p. 80). Second, since a change in the design of one component in a modular system does not require major compensating changes in the design of other components (Sanchez 1999; Stremersch et al. 2003), system modularity has the additional benefit of lowering the cost of switching component suppliers. Switching suppliers is a credible threat that buyers may use to keep their suppliers on their toes. The buyer then acts as system integrator and can select the best mix of suppliers and system components (Wuyts et al. 2004).

In summary, we expect that (1) strategic hazards affect the deployment of governance mechanisms, (2) governance mechanisms in turn affect relationship performance, and (3) the latter relationships are moderated by system modularity. In terms of the structure of the conceptual model, we expect that the effects of knowledge specificity, knowledge asymmetry, and knowledge spillover on relationship performance are mediated by governance mechanisms that buyer firms selectively deploy, and that this mediating effect is moderated by system modularity. Formally, the conceptual model is thus a moderated mediation model. Figure 1 depicts the theoretical framework.

\section{Strategic hazards and the selection of governance mechanisms}

Having outlined the building blocks of our conceptual framework, we now move to the development of hypotheses. We start with the effects of strategic hazards on the selection of governance mechanisms (output monitoring, behavior monitoring, and socialization). We denote these as "auxiliary hypotheses" because while they have received support in the previous literature, they are essential in the buildup towards the moderated mediation effects that form the core of our theory building effort (effects of strategic hazards on relationship performance via governance mechanisms, moderated by system modularity).

\section{Knowledge specificity}

In markets subject to fast-paced technological progress, specific assets (e.g., personnel and technologies dedicated to the buyer-supplier relationship) create a lock-in 
Fig. 1 Strategic hazards, governance mechanisms, system modularity, and relationship performance

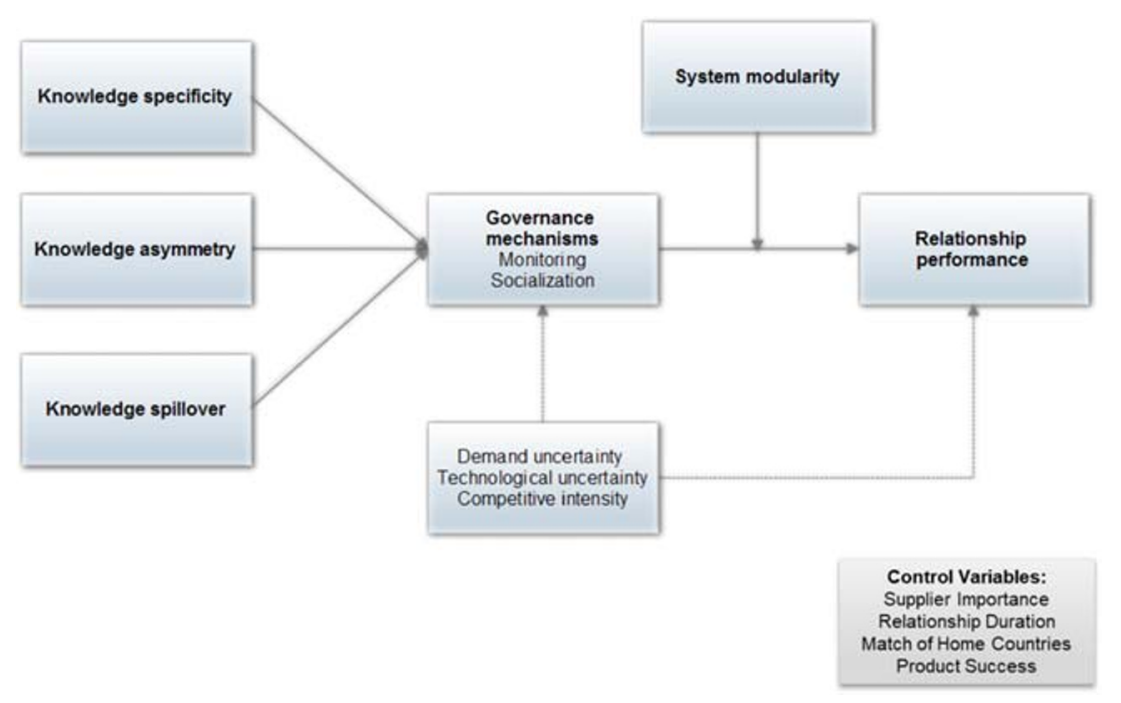

condition. Knowledge specificity represents vulnerability as the buyer firm cannot leave a given relationship without incurring high switching costs (Houston and Johnson 2000; Mooi and Ghosh 2010). Switching between suppliers may not only cause prohibitively high costs but may also result in significant delays in bringing innovations to the market (Heide and Weiss 1995). Hence, as buyers are more locked in their supply relationship, they will be motivated to sustain the relationship to economize on switching costs, giving suppliers a window of opportunity for opportunism (Kim et al. 2009; Weiss and Heide 1993). Accordingly, buyer firms face a safeguarding problem, increasing the necessity of governance mechanisms (Rokkan et al. 2003; Stump and Heide 1996).

Both monitoring and socialization may help safeguard specific assets (Celly and Frazier 1996; Wathne and Heide 2000). Buyer firms can actively monitor their suppliers and penalize opportunistic exploitation caused by knowledge specificity. Monitoring is a wellestablished control mechanism to curb opportunistic tendencies (Heide et al. 2007). Yet, we expect different effects depending on the nature of monitoring. On the one hand, behavior monitoring may enable the buyer firm to influence the process and redirect the supplier's behaviors from the outset of the relationship, thereby preventing opportunism from occurring. On the other hand, while output monitoring may help detect occurrences of opportunism, there is no credible threat to penalize opportunistic exploitation once the outcome has been realized because of prohibitive switching costs.

Socialization constitutes an alternative mechanism to cope with opportunistic exploitation of the buyer's knowledge specificity-induced vulnerability.
Establishing shared norms and values and increasing goal congruence through social interaction has been shown to be effective in coping with problems associated with knowledge specificity because it enhances the likelihood of relationship continuation (Ganesan 1994; Jap and Ganesan 2000).

H1a: Knowledge specificity is positively related to behavior monitoring and negatively related to output monitoring.

H1b: Knowledge specificity is positively related to socialization.

\section{Knowledge asymmetry}

In innovation sourcing relationships, knowledge asymmetry creates a performance evaluation problem (Eisenhardt 1985; Ouchi 1979) as the buyer's lack of insight in the sourced technology or activity to be performed by the supplier makes it difficult to verify their compliance with established agreements, appropriate behaviors, and performance standards (Heide and John 1990).

As a result of knowledge asymmetry, the buyer firm has greater difficulty detecting supplier opportunism (Kirmani and Rao 2000; Mayer and Salomon 2006). The intrinsic difficulty for a less knowledgeable buyer to evaluate the supplier's behavior and outputs may discourage the use of monitoring (Eisenhardt 1985). Since behavior monitoring entails inspections and quality control procedures (Heide et al. 2007), information asymmetry between buyer and supplier may discourage the buyer to take such initiatives. The performance evaluation problem created by information asymmetry also 
hinders a thorough evaluation of outputs. The supplier may exploit this situation and underperform with little risk of being caught (Houston and Johnson 2000) or deliver products that do not match buyer requirements (Wathne and Heide 2000). In sum, we expect that buyers are less likely to resort to either behavior or output monitoring when the degree of knowledge asymmetry is larger.

In contrast, we expect buyer firms to invest in socialization as a mechanism to mitigate knowledge asymmetry problems. Consensus building and goal alignment through direct interaction with suppliers may bridge the information gap (Eisenhardt 1985) and turn knowledge asymmetry into a strength as the buyer firm effectively accesses the supplier's expertise knowledge.

H2a: Knowledge asymmetry is negatively related to both behavior and output monitoring.

H2b: Knowledge asymmetry is positively related to socialization.

\section{Knowledge spillover}

Frazier et al. (2009) show that firms share strategically important information (i.e., with long-term performance implications) with their suppliers. A downside of information sharing is unintended knowledge leakage between exchange partners (Carson and John 2013; Stremersch et al. 2003), which could place the buyer firm at risk (Sislain and Satir 2000). The supplier may share the buyer's proprietary knowledge with a competing firm or expropriate it to develop the innovation internally (Mayer and Salomon 2006; Parmigiani and Mitchell 2009). Building on Teece (1986), Williamson (1991) contends that when investments in knowledge cannot be effectively protected, ex post incentives to embed protective governance structures increase. Monitoring, however, is unlikely to serve as a hedge against unintended knowledge leakage because knowledge misappropriation may be observed outside of the boundaries of the focal innovation project (e.g., commercial secrets) - in areas where the buyer firm has no authority to monitor its supplier. In such conditions, monitoring suppliers' behavior and/ or evaluating their performance based on tangible outcomes may become ambiguous, costly, and time-consuming (Lawless and Price 1992).

Buyers may choose to nurture their supplier relationships and invest in consensus building to protect themselves against opportunistic exploitation of their knowledge resources (Frazier et al. 2009; Wang et al. 2008). Socialization serves as a hedge against knowledge spillover as it helps align the long-term goals of the involved parties and promote relationship continuation. The emergence of relational norms and trust may discourage the component supplier to misappropriate the buyer firm's knowledge (Ganesan 1994; Williamson 1991). First, the supplier is likely to abide to the code of conduct and shared objectives; second, misappropriation may be considered as a breach of trust by the buyer firm, which would likely instigate a cycle of retaliation as mistrust begets mistrust (Morgan and Hunt 1994).

H3a: Knowledge spillover is negatively related to both behavior and output monitoring.

H3b: Knowledge spillover is positively related to socialization.

\section{Governance mechanisms, relationship performance, and system modularity}

We now develop a set of arguments explicating the effects of governance mechanisms on relationship performance, moderated by system modularity.

\section{Monitoring}

An interesting difference between behavior and output monitoring is that behavior monitoring, because of its constraining impact on how activities are to be performed, may be perceived as intrusive - especially when the monitored party is expected to act more independently (Heide et al. 2007). Behavior monitoring may even promote opportunism and cause reactance when it violates the monitored party's autonomy in task completion (Brehm 1966; Deci et al. 1999; Perrow 1986). In a modular system where task interdependency is low and firms act more autonomously, behavior monitoring may thus be perceived as intrusive and work counterproductively. Such opportunism stemming from partner reactance may negatively affect relationship performance. We therefore expect that the effect of behavior monitoring on relationship performance is weaker in more modular systems. Behavior monitoring is likely more effective in more integrated systems characterized by high task interdependency.

Output monitoring is generally considered to be less intrusive and suppliers who are at risk of being replaced by other suppliers, because of the ease of switching in more modular systems, may more readily tolerate output monitoring. Yet, even though we may not expect supplier reactance to output monitoring, also output monitoring is likely less effective in more modular systems. In integrated systems, where a supplier's tasks are intricately connected to and dependent on other parties' 
tasks, procedures for output monitoring are indispensable to delineate the supplier's tasks and specify criteria for performance evaluation. System modularity, in contrast, serves as a designed-in substitute to monitoring (c.f., Tiwana 2008). Output monitoring is not needed to delineate tasks and identify performance evaluation criteria, thanks to the standardization of interfaces which enable better task division and more autonomous task completion (Schilling 2000; Wilson et al. 1990), reducing the need to exert managerial authority for the coordination of activities (Orton and Weick 1990; Sanchez 1999). Investing resources in output monitoring when this type of control is in fact redundant and when these resources could have been invested elsewhere, may result in ineffective resource allocation and lower relationship performance. We hypothesize:

H4a: Behavior monitoring and output monitoring are associated with lower relationship performance in more modular systems.

\section{Socialization}

An interesting question arises regarding the effectiveness of socialization in modular systems. Modular systems are characterized by autonomous task completion whereas integrated systems are characterized by task interdependency. Also, modularity facilitates switching suppliers whereas integration hinders switching. It is precisely because modularity reduces joint task completion and coordination and entails a risk of switching, that we expect socialization to be a more effective response to strategic hazards in more modular systems. Socialization enables suppliers and buyers in modular systems to align goals and makes relationship continuation more attractive. While these advantages may be achieved in integrated systems via coordination and joint task completion which are inherent to integration, socialization efforts are likely more valuable in modular systems to mitigate the transaction hazards due to higher specificity, asymmetry, and leakage.

In more integrated systems socialization is likely less effective for two reasons: (1) task interdependency necessitates coordination and collaboration, thereby decreasing the need for further socialization efforts and (2) even if socialization increases the parties' understanding of goals, penalizing defiant suppliers is difficult because of the low credibility of the threat to switch suppliers, which may further undermine the effectiveness of socialization. In sum, we expect:

H4b: Socialization is associated with higher relationship performance in more modular systems.

\section{Moderated mediation hypotheses}

In the preceding sections, we developed arguments for the effects of strategic hazards on the selection of governance mechanisms and effects of governance mechanisms on relationship performance contingent on modularity. As a final step, we now formulate moderated mediation hypotheses, arguing that the consequences of strategic hazards for relationship performance are mediated by the deployment of governance mechanisms, and that this indirect effect is moderated by modularity. An advantage of this approach is that it will allow us to examine under which conditions strategic hazards turn into strategic opportunities.

\section{Knowledge specificity}

We expect a negative moderated mediation effect of knowledge specificity on relationship performance via behavior monitoring. Knowledge specificity is expected to stimulate firms to engage in behavior monitoring, yet the effect of behavior monitoring on relationship performance is less favorable in more modular systems. When firms act more autonomously they are more likely to perceive behavior monitoring in response to knowledge specificity as intrusive, since it is explicitly intended to constrain the suppliers' latitude of action; the reactance this may trigger may harm relationship performance, and amplify rather than resolve the lock-in problem. Hence, we expect that behavior monitoring is a less effective response to knowledge specificity in more modular systems, where suppliers act in a more autonomous fashion while completing the innovation tasks. We expect a positive moderated mediation effect of knowledge specificity on relationship performance via output monitoring. This positive effect results from the multiplication of a negative effect of knowledge specificity on output monitoring (based on the argument that output monitoring does not allow for redirecting the supplier's behavior, see H1a) and a negative interaction effect between output monitoring and modularity (based on the argument that output monitoring is less effective in more modular systems because system modularity inherently involves task delineation and the specification of performance criteria - making output monitoring redundant, see $\mathrm{H} 4 \mathrm{a}$ ).

In contrast, we expect a positive moderated mediation effect of knowledge specificity on relationship performance via socialization. As knowledge and the embodiments of knowledge (such as personnel, equipment, and systems) are tailored to the supplier, socialization may serve as an effective hedge (H1b), especially in more modular systems where interfaces are standardized (H4b). In integrated systems, the intricate dependencies among system components may obviate the relational benefits associated with socialization.

H5a: System modularity weakens the positive indirect effect of knowledge specificity on relationship performance via behavior monitoring, and weakens the negative 
indirect effect of knowledge specificity on relationship performance via output monitoring.

H5b: System modularity strengthens the positive indirect effect of knowledge specificity on relationship performance via socialization.

\section{Knowledge asymmetry}

We expected knowledge asymmetry to reduce reliance on monitoring (H2a), due to the difficulty of monitoring the supplier's behaviors and assess its outputs. Since monitoring is less effective in modularized systems than in integrated systems ( $\mathrm{H} 4 \mathrm{a})$, because of the increased task autonomy granted to component suppliers in more modular systems, we expect a positive moderated mediation effect (multiplication of a negative effect of knowledge asymmetry on monitoring, and a negative moderation effect of both types of monitoring on relationship performance). In other words, the reduced monitoring in response to knowledge asymmetry benefits relationship performance in more modular systems.

In contrast, we expect a positive effect of knowledge asymmetry on relationship performance via socialization, which is likely stronger in more modular systems. Socialization results in shared goals, values, and norms and thereby creates an informal bond among otherwise autonomously operating supplier and buyer (whereas in more integrated systems, the inherent task interdependencies obviate the need for additional socialization in response to knowledge asymmetry). In other words, we expect a positive moderated mediation effect (i.e., the multiplication of a positive indirect performance effect of knowledge asymmetry via socialization $(\mathrm{H} 2 \mathrm{~b})$, and a positive moderation effect of modularity (H4b)).

H6a: System modularity weakens the negative indirect effect of knowledge asymmetry on relationship performance via behavior monitoring and via output monitoring.

H6b System modularity strengthens the positive indirect effect of knowledge asymmetry on relationship performance via socialization.

\section{Knowledge spillover}

Monitoring (under whichever form) is unlikely an effective response to knowledge spillover since knowledge expropriation occurs outside of the scope of the focal relationship, making monitoring essentially useless (H3a). Since monitoring is expected to be less effective in more modular systems $(\mathrm{H} 4 \mathrm{a})$, we expect a positive moderated mediation effect (multiplication of a negative effect of knowledge spillover on monitoring, and a negative moderation effect of both types of monitoring on relationship performance).
Socialization, in contrast, may be an effective response to knowledge spillover as system modularity increases. Respecting social norms and abiding to agreed-upon joint goals may be more attractive than opportunistically misappropriating buyer knowledge $(\mathrm{H} 3 \mathrm{~b})$, even if the opportunity presents itself in more modular systems. This may enhance relationship performance through allowing hazard-free knowledge sharing across firm boundaries. In summary, knowledge spillover, often denoted as a hazard only, is expected to contribute to relationship performance via the deployment of socialization and this mediated effect is likely stronger in more modular systems $(\mathrm{H} 4 \mathrm{~b})$, implying a positive moderated mediation effect.

H7a: System modularity weakens the negative indirect effect of knowledge spillover on relationship performance via behavior monitoring and via output monitoring.

H7b: System modularity strengthens the positive indirect effect of knowledge spillover on relationship performance via socialization.

\section{Methodology}

\section{Sampling}

We prepared a survey instrument to collect the data required to test our hypotheses. Our sampling frame was a list of 1298 North American buyer firms provided by a commercial vendor. We used two selection criteria to identify potential respondents. First, we selected all firms active in technology-intensive industries (biotechnology, computer hardware and software, telecommunications, pharmaceuticals, and automotive) because external sourcing and modular systems are prevalent across innovation projects in such industries (Choudhury and Sabherwal 2003). Second, we selected those firms for which we could identify individuals ranked as manager or higher (in marketing, $R \& D$, business development, engineering, operations, and/ or production). Managers at such ranks and functions oversee firms' decisions to engage in supplier relationships and build modular systems.

Each firm was first contacted by phone to encourage participation of the correct key informant prior to sending the survey. The telephone conversations also allowed us to fine-tune the sample and select respondents based on their involvement in a recent product innovation project involving sourcing relationships (with the new product being on the market for three years or less). 663 respondents fit our screening criteria. The subsequent data collection was via a mailing conducted by a professional market research firm, generating 194 usable questionnaires (for a response rate of 29.3\%). Respondents were employed in manufacturing $(N=63)$, 
Table 2 Descriptive information about the measures

\begin{tabular}{|c|c|c|c|c|c|c|c|c|c|c|c|c|c|c|c|}
\hline & 1. & 2. & 3. & 4. & 5. & 6. & 7. & 8. & 9. & 10. & 11. & 12. & 13. & 14. & 15. \\
\hline 1. Relationship performance & 0.91 & & & & & & & & & & & & & & \\
\hline 2. Behavior monitoring & $0.41 *$ & 0.90 & & & & & & & & & & & & & \\
\hline 3. Outcome monitoring & $0.48^{*}$ & $0.64^{*}$ & 0.93 & & & & & & & & & & & & \\
\hline 4. Socialization & $0.37 *$ & $0.63^{*}$ & $0.55^{*}$ & 0.90 & & & & & & & & & & & \\
\hline 5. Knowledge asymmetry & $0.31 *$ & $0.47 *$ & $0.31 *$ & $0.50 *$ & 0.83 & & & & & & & & & & \\
\hline 6. Knowledge specificity & $-0.50 *$ & $-0.50 *$ & $-0.62 *$ & $-0.54^{*}$ & $-0.38^{*}$ & 0.76 & & & & & & & & & \\
\hline 7. Knowledge spillover & $0.42 *$ & $0.45^{*}$ & $0.35^{*}$ & $0.57 *$ & $0.61^{*}$ & $-0.54 *$ & 0.78 & & & & & & & & \\
\hline 8. System modularity & $0.25^{*}$ & $0.34^{*}$ & $0.32 *$ & $0.42 *$ & $0.36^{*}$ & $-0.43^{*}$ & $0.49 *$ & 0.80 & & & & & & & \\
\hline 9. Supplier importance & $0.14^{*}$ & $0.13^{*}$ & 0.04 & -0.01 & 0.08 & -0.05 & $0.14 *$ & $0.14^{*}$ & NA & & & & & & \\
\hline 10. Relationship duration & 0.02 & 0.07 & 0.01 & -0.01 & 0.05 & -0.02 & 0.06 & 0.05 & 0.07 & NA & & & & & \\
\hline 11. Country dummy & -0.02 & 0.02 & 0.01 & -0.05 & -0.02 & -0.03 & 0.03 & 0.06 & 0.11 & 0.04 & NA & & & & \\
\hline 12. Product success & $0.50^{*}$ & $0.25^{*}$ & $0.26^{*}$ & $0.31 *$ & $0.17^{*}$ & $-0.21 *$ & $0.30^{*}$ & $0.14^{*}$ & 0.01 & 0.10 & 0.03 & NA & & & \\
\hline 13. Demand uncertainty & $0.33^{*}$ & $0.33^{*}$ & $0.23 *$ & $0.25^{*}$ & $0.28^{*}$ & $-0.24 *$ & $0.26^{*}$ & $0.36^{*}$ & $0.22 *$ & 0.10 & 0.05 & $0.34^{*}$ & 0.88 & & \\
\hline 14. Technological turbulence & $0.23 *$ & $0.35^{*}$ & $0.30 *$ & $0.35^{*}$ & $0.48^{*}$ & $-0.32 *$ & $0.46^{*}$ & $0.47 *$ & $0.17 *$ & 0.12 & -0.01 & $0.16^{*}$ & $0.28^{*}$ & 0.87 & \\
\hline 15. Competitive intensity & $0.19 *$ & $0.38^{*}$ & $0.51 *$ & $0.44 *$ & $0.34 *$ & $-0.43^{*}$ & $0.35^{*}$ & $0.43^{*}$ & 0.05 & 0.09 & 0.01 & 0.08 & $0.18^{*}$ & $0.60^{*}$ & 0.84 \\
\hline M & 4.64 & 4.74 & 5.25 & 5.05 & 3.04 & 4.33 & 4.54 & 4.78 & 24.55 & 6.76 & NA & NA & 4.36 & 4.54 & 5.02 \\
\hline SD & 1.27 & 1.25 & 1.11 & 1.24 & 1.10 & 1.17 & 1.08 & 0.93 & 25.15 & 7.70 & NA & NA & 1.20 & 1.27 & 1.08 \\
\hline Composite reliability & 0.95 & 0.89 & 0.93 & 0.89 & 0.73 & 0.82 & 0.75 & 0.71 & NA & NA & NA & NA & 0.87 & 0.86 & 0.82 \\
\hline
\end{tabular}

(*) indicates correlations significant at $p<.05(r>.12$ or $r<-.12 ; N=194)$. Square root of Average Variance Extracted are the diagonal elements and inter-construct correlations are the off-diagonal elements

general management $(N=38), \mathrm{R} \& \mathrm{D}(N=27)$, marketing/ service/sales $(N=19)$, engineering $(N=15)$, and business/corporate development $(N=14){ }^{4} 59 \%(41 \%)$ of respondents in management functions were midlevel (senior-level) managers. While all buyer firms in our sample were US based, $38 \%$ of supplier firms were located across 25 countries $^{5}$ (and 62\% US based). On average, buyer firms were 43.7 years old, had 10,500 employees, and \$135 million annual sales. Buyer firms allied with supplier firms, which had an average of 2050 employees, and contributed to an average of $25 \%$ of their total sales. The mean duration of the sourcing agreements was 6.8 years. Three out of four agreements were deemed successful by the respondents. $T$-tests revealed that respondent firms which reported successful agreements did not differ significantly from those reporting unsuccessful agreements, on firm characteristics including number of employees $(\mathrm{t}=-1.800$, $p=-.08)$, number of suppliers $(\mathrm{t}=-.691, p=.49)$, annual sales $(\mathrm{t}=.048 ; p=.83), \mathrm{R} \& \mathrm{D}$ as percentage of sales $(\mathrm{t}=1.915, p=.17)$, and percentage of sales $(\mathrm{t}=1.036$,

\footnotetext{
${ }^{4}$ The remaining 18 respondents did not report their functional affiliation.

${ }^{5}$ Australia, Austria, Canada, China, Colombia, France, Germany, Hong Kong, Hungary, India, Iran, Iraq, Israel, Japan, Malaysia, Mexico, Netherlands, New Zealand, Russia, Spain, Switzerland, Taiwan, Thailand, UK, and Vietnam.
}

$p=.31)$ and profits generated by new products $(\mathrm{t}=$ $3.513, p=.06)$. Regarding the nature of sourcing, $35.6 \%$ of technologies and components were licensed and/or patented, $21.1 \%$ were developed by the supplier, and $39.2 \%$ were developed jointly by supplier and focal firm.

\section{Measurement}

To create and validate the survey items, we conducted field interviews and reviewed the scholarly literature. All measures are based on or adapted from measures used in prior research. Appendix Table 6 lists all measures, and Table 2 reports the descriptive statistics and correlations among the constructs. All items were specified as reflective indicators based on 7-point scales. Our measure of the dependent variable, 'relationship performance', not only incorporates if the relationship has been worthwhile and delivered fair benefits and returns, but also includes its strategic impact on key outcome variables such as profits and competitive advantage (in line with Griffith et al. 2017; Palmatier et al. 2007). We based the measures of 'behavior monitoring' and 'output monitoring' on Carson (2007) and Tiwana and Keil (2007). 'Socialization' was measured with three items adapted from Carson (2007). The seven-item measure of 'system modularity' was based on Ghosh et al. (2006). The 'knowledge specificity' measure was based on Anderson and 
Weitz (1992) and Heide and John (1990) and reflects both embedded knowledge (specific investments in personnel and training) and embodied knowledge (specific investments in production systems and equipment). We measured 'knowledge asymmetry' and 'knowledge spillover' using items from Petersen et al. (2003) and Stremersch et al. (2003). The knowledge asymmetry measure captures (the inverse of) the buyer's familiarity and understanding of the supplier's capabilities and tasks whereas knowledge spillover measures the intensity of communication and information sharing as well as susceptibility to leakage. We controlled for 'demand uncertainty', 'technological turbulence' and 'competitive intensity', using metrics from Carson (2007) and Zhou et al. (2005). We further controlled for supplier importance (\% sales coming from the supplier as percent of total sales of the company), relationship duration (number of years since the outsourcing agreement was established), the match between the home-country of the focal and partner firm (a binary variable coded $1(0)$ if the supplier had the same (different) home country as the focal firm; Stremersch et al. $2003)^{6}$ and product success (a binary variable coded 1 if the profitability goal set for the developed product was met). The initial survey was pretested among 3 expert academics and 3 upper-level managers, which lead to a few minor edits.

\section{Measure validation}

We validated the multi-item scales according to standard procedures for reflective construct measurement (Bagozzi and Yi 2011). Given the substantive goal of our study (i.e., to examine the nature of relationships between constructs rather than to understand the structure of a construct) and the complexity of our model versus sample size, we followed previous research on parceling (Bagozzi and Edwards 1998; Little et al. 2002) to assess measure reliability and validity. ${ }^{7}$ In this regard, we first assessed the unidimensionality of our constructs using exploratory factor analyses and deleted items that have low item-to-construct loading and that load on multiple constructs. Once unidimensionality was established, we formed composite indicators by averaging random pairs of source items (Bagozzi and Edwards 1998) listed in Appendix Table 6 to further assess measurement quality in a complete model. A similar

\footnotetext{
${ }^{6}$ Foreign-market operations create operational difficulties and outcome uncertainty because of spatial separation and a lack of understanding of formal and informal institutions (Boeh and Beamish 2012; Zaheer 1995). Such valueclaiming risks may be more intense when collaboration occurs on a global scale, because there are international differences in the protection of intellectual property.

${ }^{7}$ Following previous work in marketing strategy (e.g., Özturan et al. 2014), we use source item averages rather than parcels in the path analysis. Even though parceling is not uncommon for the purpose of measure validation, we prefer to use the original source items in path analysis to ensure construct validity and consistency with previous work.
}

parceling approach was used in Jasmand et al. (2012) and Schmitz et al. (2014).

Overall statistics for the complete measurement model indicated sufficient fit: $\chi_{(197)}^{2}=458.1(p<.01)$, Root Mean Square Error of Approximation $($ RMSEA) $=.06$, Comparative Fit Index $(\mathrm{CFI})=.95$, Tucker-Lewis Index $(\mathrm{TLI})=.93$, Standardized Root Mean Square Error $($ SRMR $)=.04$. We checked convergent validity using Fornell and Larcker's (1981) average variance extracted (AVE) measure. The AVE values for all constructs appear in the Appendix and are adequately high (> .50). We assessed discriminant validity in two ways. First, we compared the square root of the AVE (i.e., the diagonals in Table 2) with the correlations among constructs (i.e., the off-diagonal elements in Table 2), following Fornell and Larcker (1981). An examination of Table 2 reveals that the diagonal values are significantly greater than the off-diagonal values, indicating that each construct shares more variance with its measures than with other constructs. Second, we performed a series of chi-square difference tests that compare models in which a factor correlation parameter was fixed to unity with models where it is set free (Anderson and Gerbing 1988). Unconstrained models fit the data better than the constrained ones, confirming discriminant validity. All factor intercorrelations, reliabilities, and descriptive statistics are provided in Table 2.

\section{Common method bias}

To reduce the severity of simultaneity issues that may cause common method and endogeneity problems, we established temporal separation between the explanatory and dependent variables in our survey instrument. We instructed respondents to report on performance measures for the current time period about a specific product development project, which was recently completed by the project team not longer than 3 years ago.

To further underscore that common method bias is not a concern in our study, we conducted several tests suggested by Podsakoff et al. (2012). First, the errors of the exogenous constructs were freed to covary with the errors of the endogenous constructs. This test was extrapolated from the equivalence testing model of Myers et al. (2000) and provides a check for instrument bias across exogenous and endogenous constructs. A significant improvement in overall model fit would suggest the presence of inference-preventing bias. We did not obtain such a result, which serves as further evidence that our model does not suffer from common method variance bias. Second, we followed Lindell and Whitney's (2001) and Malhotra et al.'s (2006) recommendations and used the common marker variable 
(CMV) technique. Since we did not identify a marker variable a priori, we used the smallest correlation among the manifest variables as proxy. The correlation of competitive intensity with demand uncertainty was $.181, p=.012$. Using this as the discount factor, we adopted the formula and corresponding $t$-statistic proposed by Malhotra et al. (2006, p.1868):

$r_{A}=\frac{r_{U}-r_{M}}{1-r_{M}} \quad$ and $\quad t_{\frac{a}{2}, n-3}=\frac{r_{A}}{\sqrt{\left(1-r_{A}^{2}\right) /(n-3)}}$

where $r_{A}$ is the adjusted correlation coefficient, $r_{M}$ is .181, and $r_{U}$ is the uncorrected (observed) correlation. We compared adjusted correlations among our focal constructs with the uncorrected correlations and found no differences in the pattern of signs and significances, providing additional support that CMB is not a concern in this study.

Lastly, it is important to note that most hypothesized effects $(\mathrm{H} 4 \mathrm{a}-\mathrm{H} 7)$ are contingency effects. Our focus on moderated mediation effects alleviates common method bias concerns as the prior literature has amply demonstrated that interaction effects cannot be an artifact of common method bias (see Evans 1985, for a Monte Carlo study; see Siemsen et al. 2010, for an analytical derivation). Recent overview studies of common method bias in social science research (e.g., Podsakoff et al. 2012) and recent applications in marketing (e.g., Korschun et al. 2014) converge that common method bias is not a concern for the test of moderation hypotheses.

\section{Omitted variables induced endogeneity bias}

It is possible that certain unmeasured variables that reflect prior strategic decisions are associated with both a firm's use of modular systems and the extent to which it benefits from supply relationships. One such variable may be alliance experience, which likely affects both the use of modular systems and relationship performance. We tested for potential endogeneity of modularity using an instrumental variables regression model with a two-stage least squares (2SLS) estimator (Basmann 1957; Stock and Watson 2011).

In a first-stage model, we regressed modularity on all exogenous variables in the model and a set of instrumental variables. As instruments for modularity, we included the buyer firm's size (i.e., annual sales and number of employees), supply concentration (i.e., the inverse of the number of other suppliers from whom the buyer firm has acquired components for the specific outsourced technology), the type of the outsourced technology (licensed and patented technology, technology developed by the supplier, technology jointly developed by buyer and supplier), and the age of the company. Since modularity is beneficial for firms which target multiple market segments, larger firms may be more likely to implement modular systems (Ethiraj and Levinthal 2004; Worren et al. 2002). Also supply concentration and technology type likely affect firms' decisions to develop modular systems (Griffith et al. 2009; Schilling 2000; Stremersch et al. 2003; Wilson et al. 1990) but are driven by other variables not under the immediate control of project managers. Organizations with a longer history may be less adept at making the transition from traditional integrated systems to more modular systems and reaping the strategic advantages associated with modularity (Danese and Filippini 2013). In sum, we expect that firm size, supply concentration, technology type and company age are relevant (associated with modularity) and exogenous (unlikely related with unexplained variance in relationship performance).

Following Papies et al. (2017), we tested the relevance of the instruments by examining the explanatory power of the first-stage regression and significance of coefficient estimates for instruments. An F-test indicated that the instruments are strong $(\mathrm{F}=35.31 ; p=.00)$. A Sargan's (1958) test $\left(x^{2}=3.07\right.$; $p=.55)$ also confirmed the validity of our instruments. None of the correlations between the instruments and the residual of the second-stage (relationship performance) equation were significant. Having established the strength and validity of the instruments, we included the predicted error of modularity as control in the second-stage performance equation. We then evaluated the exogeneity of modularity by checking the significance of the coefficient estimate for the first-stage error in the second-stage equation. We ran Durbin and $\mathrm{Wu}$-Hausman tests, both of which indicated that modularity is not endogenous in our study $\left(x^{2}=.403 ; p=.53 ; \mathrm{F}=.323 ; p=.57\right)$.

\section{Sample selection induced endogeneity bias}

We also checked for potential self-selection bias using the Heckman two-step estimation approach (Chen et al. 2009). A possible source of concern is that our sample may be biased toward more innovative firms, which may in turn bias the impact of modularity on performance. Innovative firms may differ from less innovative firms regarding the characteristics of the partners, partnerships, and systems they choose for the sake of future returns. Therefore, we collected an additional sample of less innovative firms. We distinguished between more and less innovative firms as follows. Following Cooper and Kleinschmidt (1995) we categorize a firm as innovative when more than $30 \%$ of sales and $30 \%$ of profits stem from new products launched in the last three years (c.f., Cooper and Kleinschmidt 1995; Markham and Lee 2013). ${ }^{8}$ We specify a first-stage probit equation to distinguish innovative from non-innovative firms. We 
included the type of the outsourced technology, supplier concentration, the age of the company, and firm size. The more innovative the buyer firm, the higher its reluctance to relinquish control or to expose critical knowledge to their suppliers (Wathne and Heide 2000; Frazier et al. 2009). Scholars suggest that firms should protect their tacit knowhow and assets against valueclaiming risks through licensing, patenting and/or avoiding joint development or overreliance on a single supplier (Geyskens et al. 2006; Stremersch et al. 2003). Further, a large body of research in marketing, management, and innovation focuses on firm age and size as key organizational variables that drive innovation and distinguish more innovative firms (Ali 1994; Baker and Sinkula 2007).

This selection model had strong explanatory power (Wald chi-square statistic $=377.28 ; p=.00$ ). The inverse Mills ratio $\lambda$ which is calculated based on the probit regression serves as a self-selection correction parameter in the performance equation i.e., its significance is indicative of self-selection bias. We found a non-significant inverse Mills ratio $(\lambda=.313, p>.05$; respectively), indicating that self-selection bias is not a concern.

\section{Analyses and results}

We used simultaneous moderated regressions based on maximum likelihood estimation to test our moderated mediation hypotheses. The measurement items were averaged for the multi-item constructs. We mean-centered the system modularity, monitoring, and socialization measures to facilitate interpretation (Muller et al. 2005).

To examine the possible threat of multicollinearity, we used two methods. First, we calculated variance inflation factors (VIFs). All VIFs were below 3, suggesting that multicollinearity was not a concern. Second, following Kalnins (2018)'s recommendations and previous studies applying this approach (e.g., Moeen and Mitchell 2020; Zorn et al. 2020), we investigated multicollinearity among pairs of variables with correlations greater than 0.3 or lower than -0.3 . Across the 171 correlations in the matrix that includes the interactions terms, we observe that hazards are moderately correlated with the four dependent variables (e.g., knowledge asymmetry and relationship performance: $r=-.507)$. In each case, we found that dropping either variable from our models did not influence the signs or magnitudes of our moderated mediation findings. ${ }^{9}$ Overall, these analyses do not suggest that the reported results are biased by multicollinearity.

\footnotetext{
${ }^{0}$ We verified if the results were sensitive to the choice of a $30 \%$ threshold. We used alternative thresholds within the 30\%-50\% range and found that the reported results are robust when using higher threshold values.
}

\section{Model specification}

Our system of equations has the following form:

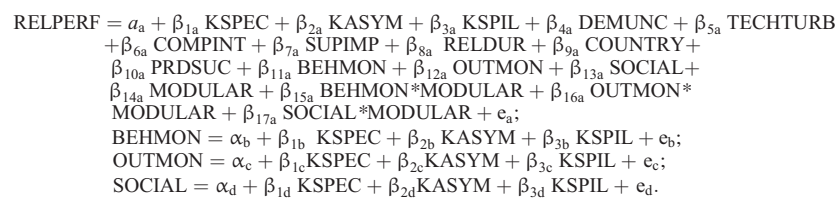

Where RELPERF = relationship performance, MODULAR $=$ system modularity, $\mathrm{BEHMON}=$ behavior monitoring, OUTMON $=$ output monitoring, SOCIAL $=$ socialization, KSPEC=knowledge specificity, $\mathrm{KASYM}=$ knowledge asymmetry, $\mathrm{KSPIL}=$ knowledge spillover, DEMUNC= demand uncertainty, TECHTURB $=$ technological turbulence, COMPINT $=$ competitive intensity, SUPIMP = supplier importance, RELDUR $=$ relationship duration, $C O U N T R Y=$ the match between the home-country of the focal and partner firm, and PRDSUC $=$ product success. $\beta_{1-6}$ are the parameter estimates of the direct effects of the strategic hazards (and control variables); $\beta_{7-9}$ are the main effects of governance mechanisms; $\beta_{10}$ is the main effect of modularity; and finally, $\beta_{11-13}$ are the parameters of the interaction effects of governance mechanisms and modularity.

To fully understand the nature of moderated mediation $^{10}$ (Muller et al. 2005; Preacher et al. 2007), we examined (a) effects of strategic hazards on governance mechanisms $\left(\beta_{1 b^{-}}-\beta_{3 b}, \beta_{1 c}-\beta_{3 c}, \beta_{1 d^{-}} \beta_{3 d}\right)$, (b) interactions between governance mechanisms and modularity in predicting relationship performance $\left(\beta_{11 \mathrm{a}}, \beta_{12 \mathrm{a}}, \beta_{13 \mathrm{a}}\right)$, and (c) conditional indirect effects of strategic hazards on relationship performance via governance mechanisms, depending on the level of modularity. We calculate the conditional indirect effects by multiplying the effects of hazards on controls (a) with the interaction effect between controls and modularity on relationship performance (b). These are the essence of moderated mediation and enable us to test whether the strength

\footnotetext{
${ }^{9}$ Also governance mechanisms and their interaction terms with modularity are moderately correlated with dependent variables (e.g., output monitoring and relationship performance: $r=.409$ ), yet testing piecewise exclusion for these variables is not possible without fundamentally altering the modeling approach.

${ }^{10}$ As Muller et al. (2005) suggest, moderated mediation occurs if the mediating process that is responsible for producing the effect of the independent variable on the outcome depends on the value of a moderator variable. If the moderator is a contextual variable (as is modularity), the mediating process (i.e., between strategic hazards and relationship performance through monitoring and socialization) varies as a function of context. In other words, moderated mediation is demonstrated when the conditional indirect effect of strategic hazards on relationship performance via governance mechanisms varies in strength, depending on the level of modularity.
} 
Table 3 Strategic hazards, governance mechanisms, and modularity path coefficients

\begin{tabular}{|c|c|c|c|c|c|c|c|c|c|c|c|c|}
\hline & \multicolumn{3}{|c|}{ Relationship performance } & \multicolumn{3}{|c|}{ Behavior monitoring } & \multicolumn{3}{|c|}{ Output monitoring } & \multicolumn{3}{|l|}{ Socialization } \\
\hline & $\beta$ & SE & $p$ & $\beta$ & SE & $p$ & $\beta$ & SE & $p$ & $\beta$ & SE & $p$ \\
\hline Knowledge specificity & 0.045 & 0.07 & 0.54 & H1a: 0.292 & 0.08 & 0.00 & H1a: 0.091 & 0.07 & 0.22 & H1b: 0.191 & 0.07 & 0.02 \\
\hline Knowledge asymmetry & -0.297 & 0.08 & 0.00 & H2a: -0.358 & 0.07 & 0.00 & H2a: -0.609 & 0.06 & 0.00 & H2b: -0.314 & 0.07 & 0.00 \\
\hline Knowledge spillover & 0.129 & 0.08 & 0.11 & H3a: 0.051 & 0.08 & 0.54 & H3a: -0.057 & 0.08 & 0.48 & H3b: 0.268 & 0.08 & 0.00 \\
\hline Supplier importance & 0.057 & 0.06 & 0.31 & - & - & - & - & - & - & - & - & - \\
\hline Relationship duration & -0.044 & 0.06 & 0.43 & - & - & - & - & - & - & - & - & - \\
\hline Country dummy & -0.013 & 0.06 & 0.81 & - & - & - & - & - & - & - & - & - \\
\hline Product success & 0.342 & 0.06 & 0.00 & - & - & - & - & - & - & - & - & - \\
\hline Demand uncertainty & 0.110 & 0.06 & 0.07 & - & - & - & - & - & - & - & - & - \\
\hline Technological turbulence & 0.043 & 0.08 & 0.56 & - & - & - & - & - & - & - & - & - \\
\hline Competitive intensity & -0.103 & 0.08 & 0.19 & - & - & - & - & - & - & - & - & - \\
\hline System modularity & 0.001 & 0.07 & 0.99 & - & - & - & - & - & - & - & - & - \\
\hline Behavior monitoring & -0.027 & 0.08 & 0.74 & - & - & - & - & - & - & - & - & - \\
\hline Output monitoring & 0.190 & 0.08 & 0.02 & - & - & - & - & - & - & - & - & - \\
\hline Socialization & -0.077 & 0.08 & 0.34 & - & - & - & - & - & - & - & - & - \\
\hline Behavior monitoring $\mathrm{x}$ Modularity & -0.160 & 0.05 & 0.03 & - & - & - & - & - & - & - & - & - \\
\hline Outcome monitoring $\mathrm{x}$ Modularity & -0.139 & 0.04 & 0.05 & - & - & - & - & - & - & - & - & - \\
\hline Socialization x Modularity & 0.193 & 0.04 & 0.01 & - & - & - & - & - & - & - & - & - \\
\hline $\mathrm{R}^{2}$ & 0.51 & 0.05 & 0.00 & 0.34 & 0.06 & 0.00 & 0.38 & 0.06 & 0.00 & 0.41 & 0.06 & 0.00 \\
\hline
\end{tabular}

Standardized solution; $p$-values are two-tailed

of mediation via governance mechanisms varies due to modularity (Preacher et al. 2007; Zhao et al. 2010).

\section{Estimation results}

Table 3 presents the estimation results. We first consider the effects of strategic hazards on governance mechanisms (H1-H3). Knowledge specificity increases the deployment of behavior monitoring $(\beta=.292, p<.01)$ and socialization $(\beta=.191, p<.05)$, but has no effect on the use of output monitoring $(\beta=.091, p=.22)$. Thus, H1b is supported, while H1a is partially supported. Knowledge asymmetry reduces the deployment of all three governance mechanisms (behavior monitoring: $\beta=-.358$; output monitoring: $\beta=-.609$; socialization: $\beta=-.314$; all $p \mathrm{~s}<.01$ ), in support of $\mathrm{H} 2$ a but rejecting $\mathrm{H} 2 \mathrm{~b}$. Finally, rejecting $\mathrm{H} 3 \mathrm{a}$, knowledge spillover does not affect behavior monitoring $(\beta=.051, p=.54)$ or output monitoring $(\beta=-.057, p=.48)$. In support of $\mathrm{H} 3 \mathrm{~b}$, knowledge spillover increases socialization $(\beta=.268$, $p<.01)$. The most surprising finding in this set of results is the negative effect of knowledge asymmetry on socialization, which contrasts with the hypothesized positive effect $(\mathrm{H} 2 \mathrm{~b})$. We expected socialization to be instrumental in bridging the information gap (Eisenhardt 1985). Perhaps the information gap created by knowledge asymmetry discourages the buyer firm to team up with the supplier to better understand its goals and values. Hence, the differences between the partners in terms of mindsets and knowhow may hinder the effective realization of socialization benefits. The unexpected negative effect has implications for our interpretation of the moderated mediation effect of knowledge specificity via socialization (see discussion section).

Next, we report on the interaction effects between modularity and governance mechanisms on performance (b), presented in rows 11-13 of Table 3. Whereas modularity exerts no direct effect on relationship performance $(\beta=.001, p=.99)$, it moderates all three relationships between governance mechanisms and relationship performance, providing first evidence of its governance role. In line with our theoretical arguments, modularity weakens the performance consequences of monitoring (behavior monitoring $\mathrm{x}$ modularity: $\beta=-.160, p<.05$; output monitoring $\mathrm{x}$ modularity: $\beta=-.139, p=.05$ ) while strengthening the performance consequences of socialization $(\beta=.193, p=.01)$. $\mathrm{H} 4 \mathrm{a}$ and $\mathrm{H} 4 \mathrm{~b}$ are supported. 
To test for moderated mediation relationships (d), we used Preacher et al.'s (2007) statistical significance test to compute a $z$-statistic for each conditional indirect effect. The conditional indirect effects are reported in Table 4. An entry in Table 4 (e.g., the parameter -.049 in the left upper cell) is the result of a multiplication of (1) the effect of the strategic hazard in the corresponding row on the control mechanism in the corresponding column (in this case, the effect of knowledge specificity on behavior monitoring: .292) and (2) the moderation effect of that control mechanism with modularity on performance (in this case, the performance effect of behavior monitoring $\mathrm{x}$ modularity: $-.160)$. Table 4 shows that the indirect effect of knowledge specificity on relationship performance through behavior monitoring is negatively moderated by modularity $(\beta=-.049 ; p=.05)$, while its indirect effect through socialization is positively moderated by modularity ( $\beta=.041 ; p<.05$ ). Hence, H5a (for behavior monitoring) and $\mathrm{H} 5 \mathrm{~b}$ are supported. The indirect effect of knowledge specificity on relationship performance through outcome monitoring was not significantly moderated by modularity $(\beta=-.013 ; p=.16)$, which is not unexpected given the insignificant direct effect of knowledge specificity on output monitoring (see above).

The directionality of the moderated mediation effects for knowledge asymmetry are the exact reverse: the moderated mediation effect of knowledge asymmetry via behavioral and outcome monitoring on relationship performance, are both positive $(\beta=.065$ and $\beta=.095$; both $p<.05$ ), supporting H6a. For interpretation purposes, it is important to note that these positive effects result from the multiplication of a negative effect of knowledge asymmetry on monitoring and a negative moderation effect of monitoring $\mathrm{x}$ modularity on relationship performance - all in line with the developed theory. Knowledge asymmetry discourages buyer firms to monitor their suppliers, which has positive consequences for relationship performance in more modular systems where suppliers may perceive monitoring being at odds with their autonomous role in task completion.
Contrary to $\mathrm{H} 6 \mathrm{~b}$, where we posited that modularity strengthens a positive indirect effect of knowledge asymmetry on relationship performance through socialization, we find evidence for a negative moderated mediation effect $(\beta=-.073 ; p<.05)$. The explanation for this negative moderated mediation effect can be derived from our above discussion of Table 3, where we reported an unexpected negative direct effect of knowledge asymmetry on socialization. Arguably, knowledge asymmetry complicates communication, thereby either discouraging efforts at socialization or hampering the effective realization of socialization. Because of this negative effect of knowledge asymmetry on socialization and a positive interaction effect between socialization and modularity on performance, the corresponding moderated mediation effect is negative.

Finally, we do not find support for moderated mediation hypothesis $\mathrm{H} 7 \mathrm{a}$ that involves knowledge spillover and monitoring (moderated mediation via behavior monitoring: $\beta=-.009 ; p=.28$; moderated mediation via output monitoring: $\beta=.009 ; p=.26$ ). We do find support for $\mathrm{H} 7 \mathrm{~b}$ though, in that modularity positively moderates the mediation link between knowledge spillover and relationship performance through socialization $(\beta=.063$; $p<.05$ ). Figures 2 and 3 depict these results.

\section{Further analyses}

To examine formally if managers incorporate modularity in their governance decisions, we estimated a rival nested model by including both direct effects of modularity on governance mechanisms and moderating effects of modularity on the relationships between strategic hazards and governance mechanisms. Model fit deteriorated significantly when these additional paths were added (Bayesian Information Criterion (BIC) deteriorated from 2264.29 to 2310.05$)$. This finding confirms that governance choices are made at the transactional level in response to hazards, while contextual variables (such as system modularity) seldom enter the equation when

Table 4 Effects of strategic hazards on relationship performance through governance mechanisms moderated by system modularity

\begin{tabular}{|c|c|c|c|c|c|c|c|c|c|}
\hline & \multicolumn{3}{|c|}{ Behavior monitoring x Modularity } & \multicolumn{3}{|c|}{ Outcome monitoring x Modularity } & \multicolumn{3}{|c|}{ Socialization x Modularity } \\
\hline & $\mathrm{b}$ & SE & $p$ & $\mathrm{~b}$ & SE & $p$ & $\mathrm{~b}$ & SE & $p$ \\
\hline Knowledge specificity & H5a: -0.049 & 0.03 & 0.05 & H5a: -0.013 & 0.01 & 0.16 & H5b: 0.041 & 0.02 & 0.04 \\
\hline Knowledge asymmetry & H6a: 0.065 & 0.04 & 0.04 & H6a: 0.095 & 0.06 & 0.05 & H6b: -0.073 & 0.04 & 0.02 \\
\hline Knowledge spillover & H7a: -0.009 & 0.02 & 0.28 & H7a: 0.009 & 0.01 & 0.26 & H7b: 0.063 & 0.03 & 0.03 \\
\hline
\end{tabular}

Unstandardized solution; $p$-values are one-tailed 
Fig. 2 Overall empirical results

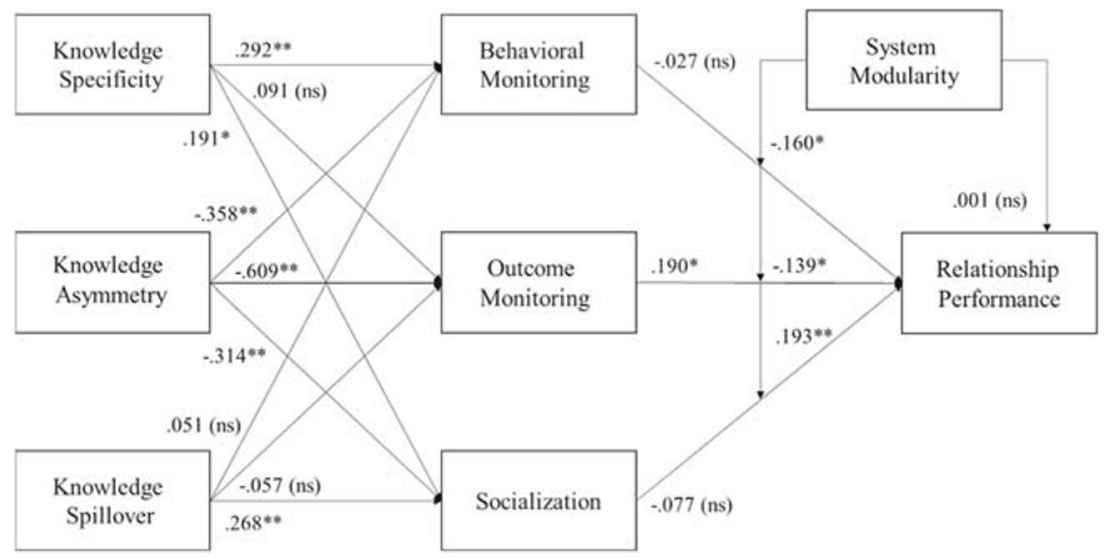

(a) KNOWLEDGE SPECIFICITY

(b) KNOWLEDGE ASYMMETRY
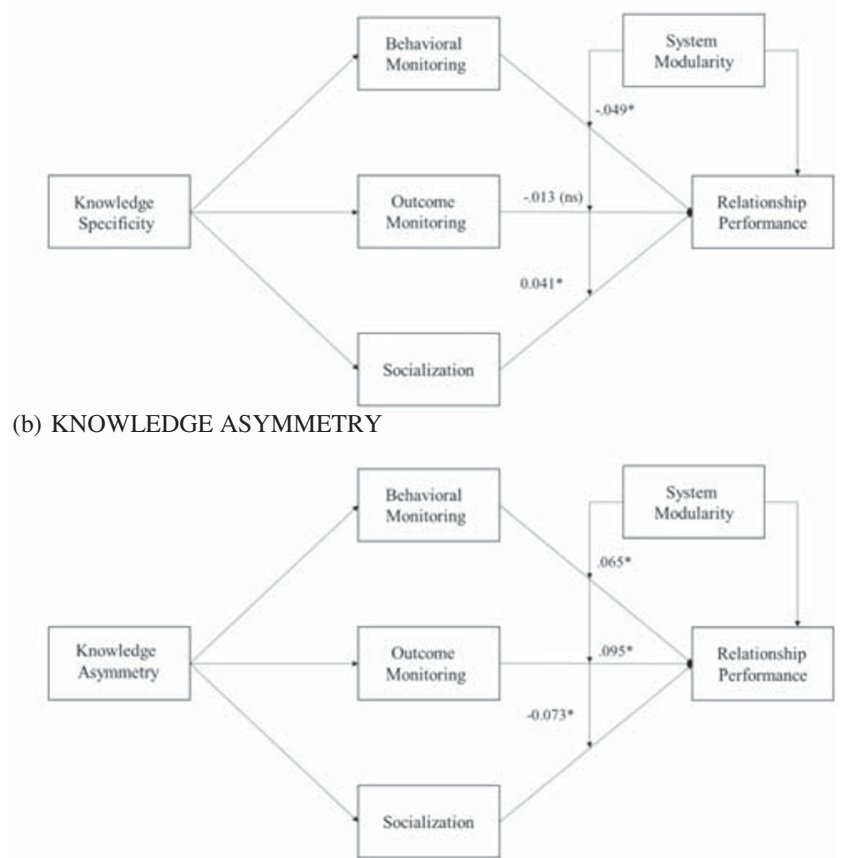

(c) KNOWLEDGE SPILLOVER

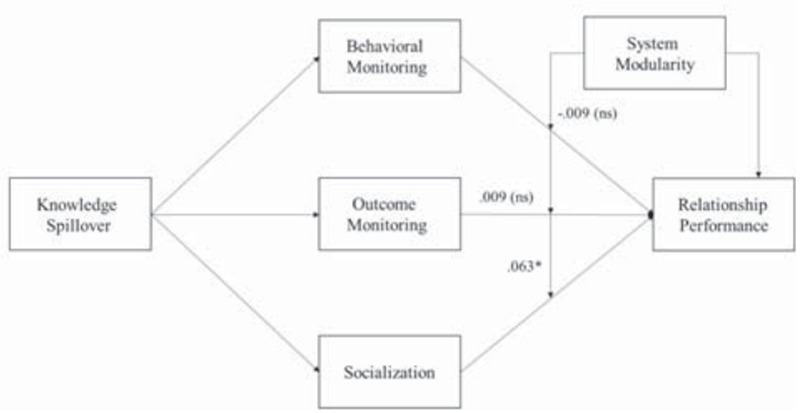

Fig. 3 Empirical results on the effects of system modularity a knowledge specificity b knowledge asymmetry $\mathbf{c}$ knowledge spillover making governance choices (c.f., Cui 2013; Grewal et al. 2010). In sum, managers do not behave optimally.

We also considered the possibility that modularity might cause strategic hazards, which we tested empirically via another rival model specifying these paths $(\mathrm{BIC}=2566.032)$. Additional paths from modularity to knowledge specificity, asymmetry, and spillover were insignificant $(\mathrm{b}=.175, p=.101 ; \mathrm{b}=-.100, p=.339$; $\mathrm{b}=.193, p=.060)$. Again, this may not come as a surprise since hazards are relationship-specific while modular architectures comprise system-level standardized interfaces. Clearly, hazards and governance mechanisms may differ across suppliers within one and the same system.

Lastly, since modularity reduces buyer dependence and switching costs, we tested whether our results hold when replacing modularity by switching costs. We estimated an alternative model with a "switching costs" construct based on our survey. ${ }^{11}$ The results indicate that the impact of switching costs on relational performance is insignificant $(\beta=.089, p=.220)$. Furthermore, switching costs do not significantly moderate the relationship between governance mechanisms (behavioral monitoring, outcome monitoring, and socialization) and performance $(\beta=.390, p=.114 ; \beta=-.333, p=.126$; $\beta=.061, p=.784)$. We reason that switching costs, while a facet of modularity, fail to capture the important efficiency gains that can be achieved and that explain

\footnotetext{
$\overline{{ }^{11} \text { We measured }}$ this variable using a 7-item scale:
}

1 Purchasing from a new supplier would require retraining for a number of our employees.

2 Developing procedures to deal effectively with a new supplier would take a lot of time and effort.

3 Developing working relationships with new suppliers would be a time-consuming process. 
why hazards can turn into opportunities when selecting the appropriate governance mechanisms contingent on system modularity.

\section{Discussion}

We consider system modularity as an important contextual variable, which determines the effectiveness of governance mechanisms managers use to mitigate strategic hazards. To accurately delineate modularity's contribution to the management of external sourcing relationships, we investigate the complete chain of links from strategic hazards to governance mechanisms to performance. This approach also allows for a detailed analysis of the performance consequences of strategic hazards. In what follows, we take this as our starting point and review the pattern of results regarding the performance consequences of strategic hazards. Subsequently, we discuss the implications of our findings for the governance literature, the modularity literature, and the management of sourcing relationships.

\section{Strategic hazards or strategic opportunities?}

To gain a better understanding of the nature of the significant moderated mediation effects, we conduct a series of simple slope analyses. Following Wuyts (2007), we set the "high" and "low" levels of system modularity at two standard deviations above and below its mean score, respectively (all values are within the boundaries of observed sample values). Table 5 presents the estimates, standard errors, and significance values of the indirect effects for strategic hazards on performance across low and high levels of modularity. Interestingly, Table 5 shows many instances of sign reversals: whether a strategic hazard enhances or decreases relationship performance through the deployment of governance mechanisms appears to be strongly determined by the degree of system modularity. What works in modular systems, is counter-productive in integrated systems, and vice versa.

The indirect effect of knowledge specificity on relationship performance through behavior monitoring is negative in the high modularity context, yet positive in a low modularity context. Knowledge specificity does not exert a significant indirect effect on performance via output monitoring. Knowledge specificity exerts a positive effect on relationship performance via socialization but only in the high modularity context; the effect turns negative in the low modularity context. In sum, the well-known hazards associated with buyer investments in personnel, training, production, and equipment that are specific to a supplier turn into strategic opportunities and increase relational and firm performance if and only if managed in alignment with system modularity.

For knowledge asymmetry, we found positive moderated mediation effects via monitoring. The simple slope analyses indicate that the effect of knowledge asymmetry via behavior monitoring is only positive in highly modular systems; monitoring effects turn negative in case of low system modularity. As reported earlier, we found a negative (rather than positive) moderated mediation effect of knowledge asymmetry on relationship performance via socialization - due to the negative direct effect of knowledge asymmetry on socialization. However, in the simple slope analysis, we observe a positive effect at low levels of modularity, while it turns negative at high levels. This indicates an important constraint on the effective realization of socialization benefits: the differences between exchange partners in terms of technological expertise and thought worlds appear to discourage efforts at socialization. This is particularly

Table 5 Effects of strategic hazards on relationship performance through governance mechanisms across low versus high levels of system modularity

\begin{tabular}{|c|c|c|c|c|c|c|c|c|c|c|}
\hline & \multirow[t]{2}{*}{ System modularity } & \multicolumn{3}{|c|}{ Behavior monitoring } & \multicolumn{3}{|c|}{ Outcome monitoring } & \multicolumn{3}{|c|}{ Socialization } \\
\hline & & $\mathrm{b}$ & $\mathrm{SE}$ & $p$ & $\mathrm{~b}$ & SE & $p$ & $\mathrm{~b}$ & SE & $p$ \\
\hline \multirow[t]{2}{*}{ Knowledge specificity } & Low Modularity & 0.118 & 0.06 & 0.06 & & & & -0.104 & 0.05 & 0.05 \\
\hline & High Modularity & -0.125 & 0.07 & 0.05 & & & & 0.090 & 0.05 & 0.08 \\
\hline \multirow[t]{2}{*}{ Knowledge asymmetry } & Low Modularity & -0.157 & 0.08 & 0.05 & -0.341 & 0.12 & 0.01 & 0.185 & 0.08 & 0.02 \\
\hline & High Modularity & 0.166 & 0.08 & 0.04 & 0.078 & 0.13 & 0.55 & -0.159 & 0.08 & 0.03 \\
\hline \multirow[t]{2}{*}{ Knowledge spillover } & Low Modularity & & & & & & & -0.158 & 0.07 & 0.03 \\
\hline & High Modularity & & & & & & & 0.135 & 0.07 & 0.05 \\
\hline
\end{tabular}

Unstandardized solution; $p$-values are one-tailed. The indirect effects are not reported for the insignificant moderated mediation effects 
harmful for relationship performance in highly modular systems where socialization has the potential to strengthen bonds with suppliers that are otherwise only connected via standardized interfaces. In sum, we identified situations in which a lack of familiarity with and understanding of supplier capabilities and task completion benefits the buyer firm. Knowledge asymmetry reduces both monitoring and socialization-resulting performance improvements may be caused by buyer firms avoiding resource allocation to inefficient governance mechanisms.

Finally, knowledge spillover does not exert indirect effects on relationship performance via monitoring. The simple slope analyses show that knowledge spillover positively affects relationship performance via socialization when modularity is high. In highly integrated systems, the effect of knowledge spillover through socialization is negative. A possible explanation is that interaction imposed by task interdependencies in integrated systems is dominated by the economic imperative, covering information exchange required for the integrated system to function. Adding a social layer opens the door to the exchange of more sensitive knowledge, which can hurt relationship performance. In multilayered relationships, norms of the constituent layers (task interdependency and socialization) are "almost invariably in a certain amount of conflict with one another" (Ross and Robertson 2007, p. 117). The free exchange of sensitive and tacit knowledge enabled by socialization may conflict with the formal interaction based on task interdependence. In sum, the right mix of governance and modularity can turn intensive communication and knowledge sharing by a buyer firm rich in proprietary knowledge into a performance-enhancing strategic opportunity.

The sign reversals displayed in Table 5 underscore the importance of system modularity for a correct assessment of the performance consequences of strategic "hazards".

The combined results provide some interesting novel insights. First, we can generally conclude that there is a match between socialization and system modularity (observed across all three moderated mediation effects) but a mismatch between monitoring and system modularity (observed in the case of knowledge specificity and knowledge asymmetry). Second, depending on the governance mechanisms that are selected and the degree of modularity of the system in which they are deployed, all three strategic "hazards" have the potential to contribute to relationship performance. In an exploratory fashion, we provided interpretations and discussion which may help build a more expansive theory of governance, beyond its traditional focus on negative consequences (in particular, opportunistic exploitation and knowledge misappropriation). In the next section, we elaborate on the implications for the governance literature.

\section{Implications for the governance literature}

ecision makers should account for the context within which their governance decisions are deployed, in order to better assess their future returns. The linkages between strategic hazards, governance mechanisms, and relationship performance are not universal. Whereas previous marketing channels research has incorporated the market, industry, and network context in which exchange relationships are embedded (Kim et al. 2011; Uzzi 1996; Wuyts and Geyskens 2005), we highlight a different, and more immediate, aspect of context: the multi-component system to which a given supply relationship contributes. Such a context-embedded perspective contributes to the governance literature, which suggests generic "optimal" linkages between transaction characteristics (e.g., knowledge specificity) and governance mechanisms (e.g., monitoring) (Teece 1986; Williamson 1991). Our study shows that generic linkages may be misguiding: our insights suggest that scholars should search for context-specific linkages. Our findings may encourage governance scholars to consider alternative system characteristics, other than modularity (e.g., new product team composition, opensource systems versus closed systems).

Considering system modularity as a moderator sheds new light on three knowledge variables traditionally considered to be strategic hazards. According to transaction cost economics, knowledge specificity, asymmetry, and spillover are all relational hazards against which firms ought to hedge. Even though this perspective is valuable, it is incomplete. We reason from a knowledge accessibility perspective, that knowledge specificity, asymmetry, and spillover all have the potential to enhance rather than constrain relationship performance. We provide empirical evidence that, indeed, all three "hazards" contribute to firm performance when appropriately aligned with governance mechanisms and with system modularity. Knowledge specificity signals commitment. When a firm invests in assets specific to a supplier relationship, the supplier may reciprocate with firm-specific investments, thereby contributing to a productive exchange relationship. Knowledge asymmetry provides buyers access to non-redundant knowledge. As the knowledge asymmetry gap between a firm and a supplier widens, the firm can seize the opportunity to extend its proprietary resource base with external (supplier) resources. Knowledge spillover allows for 
knowledge integration and recombination across organizational boundaries. As more knowledge is shared, buyer firms may gain valuable insights for problem solving and the generation of creative solutions.

\section{Implications for the management of innovation sourcing relationships}

Our findings indicate that knowledge specificity, asymmetry, and spillover hazards within an innovation project have consequences beyond the individual project and affect relationship performance. Their effects can be either performance-enhancing or performancedestroying. Alignment of governance choices with strategic hazards and with the degree of system modularity determines the contribution of a sourcing relationship to a firm's relational rents and market performance. The evidence provided by additional analyses that managers fail to incorporate the degree of system modularity when making governance choices in response to strategic hazards, underscores the importance of these insights for the management of sourcing relationships. This can be further analyzed through experimental research design.

\section{Limitations and future research}

A first limitation of our empirical study is that we collected our data only at the buyer side. While our focus on the buyer firm may justify a single-informant approach, the scope of inquiry could be extended by also considering the consequences of hazards, controls, and modularity for component suppliers. Second, a more direct approach to address potential endogeneity problems would be to incorporate additional variables that are currently omitted from our model and that may affect both independent and dependent variables. Alliance experience is one such variable. While we were unable to collect alliance data, due to a confidentiality-related constrain in survey administration, future research may be able to match data on hazards, governance mechanisms, and modularity with data on alliance activity. Finally, our cross-sectional study does not allow us to provide unequivocal proof of causality. For example, we cannot exclude the possibility that socialization has an impact on the degree of knowledge spillover. While we adopt the common viewpoint that transactional hazards influence governance choices, rather than the reverse, experimental or longitudinal research may be more suitable for causal inference.

Our results also raise other important research questions: First, we have two surprising results: knowledge asymmetry has a negative direct effect on socialization as well as a negative moderated mediation effect on relationship performance via socialization. Based on prior research, we expected buyer firms to invest in socialization as a mechanism to bridge the information gap, build consensus and align relationship goals. We interpret the observed negative effects as indication that the differences in terms of technological expertise and thought worlds may actually result in the lack of mutual understanding of goals, values, and norms. This may discourage communication and information sharing, thereby hampering the effective realization of socialization. Our interpretation largely relies on an understudied aspect of interorganizational exchange and governance: differences in thought worlds. While previous research has demonstrated that such differences can hinder learning and innovation in interorganizational relationships (e.g., Wuyts et al. 2005), its consequences for socialization and relational benefits deserves more research attention.

Second, while we focused on relationship performance as an important outcome variable at the buyer-supplier dyad level, future research may expand the scope of inquiry and examine system-level outcome variables. As Homburg et al. (2020) recently demonstrated, firms' efforts at building and fostering marketing ecosystems are manifestations of a strategic emphasis that contributes to marketing excellence. The phenomenon of modular systems created to enable the development of new market offerings, which are studied here, bears similarities with what Homburg, Theel, and Hohenberg call an offering-based marketing ecosystem (p.9). At the system level, several questions remain unanswered including questions of governance. Which alternative governance mechanisms operate at the system level? Should other stakeholders be considered in the management and governance of modular systems, such as business-to-business customers or other parties outside of the supply chain? Are more decentralized system approaches preferable, such as open-source platforms or systems centered on knowledge transfer?

Third, future research may study system characteristics other than modularity to further examine the context-specificity of the "discriminating alignment" hypothesis. Our theory and empirical test are limited to the chosen context of innovation sourcing relationships and by our focus on one contextual factor, namely system modularity. It may be interesting to investigate other system characteristics including new product team composition, cultural and institutional context, network characteristics of systems (such as centralization and density) through cross-sectional or experimental design.

Acknowledgements The authors would like to acknowledge the Institute for the Study of Business Markets at Pennsylvania State University for their research funding support. In addition, the authors would like to thank David A. Griffith and Steven H. Seggie for their comments on prior versions of this manuscript. 


\section{Appendix}

Table 6 Measures

\begin{tabular}{|c|c|c|}
\hline Construct & Scale items & $\mathrm{AV}$ \\
\hline $\begin{array}{l}\text { Relationship } \\
\text { perfor- } \\
\text { mance }\end{array}$ & $\begin{array}{l}\text { 1. The relationship with the supplier has been productive. } \\
\text { 2. The relationship with the supplier has been worthwhile. } \\
\text { 3. The benefits and returns from the relationship have been fair. } \\
\text { 4. The outsourcing relationship contributed to the company's core capabilities. } \\
\text { 5. The outsourcing relationship has contributed to the company's profits. } \\
\text { 6. The outsourcing relationship has contributed to the company's market share. } \\
\text { 7. The outsourcing relationship has contributed to the company's competitive advantage. }\end{array}$ & .83 \\
\hline $\begin{array}{l}\text { Behavior } \\
\text { monitoring }\end{array}$ & $\begin{array}{l}\text { 1. The supplier's work was monitored closely by our people. }{ }^{\text {a }} \\
\text { 2. The supplier was required to file extensive reports on its work during the project. }{ }^{\text {a }} \\
\text { 3. Frequent milestones were used in the relationship. }{ }^{\text {a }} \\
\text { 4. We explain to our supplier how their jobs should be done. } \\
\text { 5. We carefully define what jobs our supplier is to do. } \\
\text { 6. We develop procedures to guide our supplier's work. } \\
\text { 7. We give our supplier specific work assignments. }\end{array}$ & .80 \\
\hline $\begin{array}{l}\text { Outcome } \\
\text { monitoring }\end{array}$ & $\begin{array}{l}\text { 1. We let our supplier know what's considered good job performance. } \\
\text { 2. We give our supplier extensive feedback about how they are doing. } \\
\text { 3. We placed significant weight on timely project completion. } \\
\text { 4. We placed significant weight on completion within budgeted costs. } \\
\text { 5. Our supplier contract included technical or engineering specifications for the technology to be delivered. }{ }^{\text {a }} \\
\text { 6. Our supplier contract included performance specifications for the technology to be delivered. }{ }^{\text {a }} \\
\text { 7. Our supplier contract included specifications for milestones and/or milestone deliveries. }{ }^{\text {a }}\end{array}$ & .87 \\
\hline Socialization & $\begin{array}{l}\text { 1. Our company actively participated in project meetings to understand the project team's goals, values and norms. } \\
\text { 2. Our company placed a significant weight on understanding the project team's goals, values and norms. } \\
\text { 3. Our company attempted to understand the project team's goals, values and norms. }\end{array}$ & .81 \\
\hline $\begin{array}{l}\text { Degree of } \\
\text { modularity }\end{array}$ & $\begin{array}{l}\text { 1. In our principal industry, there are widely accepted standards for system components. } \\
\text { 2. In our development systems, product interfaces between functional components are standardized. } \\
\text { 3. In our development systems, product interfaces are specified to allow the substitution of a range of variations in components } \\
\text { into the product architecture. } \\
\text { 4. Component designs are tightly coupled in the sense that a change in the design of one component within an assembly of } \\
\text { components will require changes in the designs of other components. } *^{\mathrm{a}} \\
\text { 5. Component designs within our product architecture are loosely coupled allowing the mixing and matching of components. } \\
\text { 6. Our product architecture is complex and difficult to modify. } *^{\mathrm{a}}\end{array}$ & .64 \\
\hline $\begin{array}{l}\text { Knowledge } \\
\text { specificity }\end{array}$ & $\begin{array}{l}\text { 1. We have made a substantial investment in personnel dedicated to our relationship with this supplier. } \\
\text { 2. Training and qualifying this supplier has involved substantial commitments of time and money. } \\
\text { 3. Our production system has been tailored to using the particular items bought from this supplier. } \\
\text { 4. We have made significant investments in tooling and equipment dedicated to our outsourcing relationship. } \\
\text { 5. The transferability of such investments to an alternative supplier will be very limited. } \\
\text { 6. We could easily complete work in-house if the relationship with the supplier broke down. } *^{\mathrm{a}} \\
\text { 7. Our production system can be easily adapted to using components from a new supplier. }{ }^{\mathrm{a}}\end{array}$ & .69 \\
\hline $\begin{array}{l}\text { Knowledge } \\
\text { asymmetry }\end{array}$ & $\begin{array}{l}\text { 1. How familiar was your company with this supplier's capabilities prior this project? *b } \\
\text { 2. Our company can accurately measure the work of the supplier project team. * } \\
\text { 3. Our company understands the tasks that the supplier project team members must perform. * }\end{array}$ & .58 \\
\hline $\begin{array}{c}\text { Knowledge } \\
\text { spillover }\end{array}$ & $\begin{array}{l}\text { 1. Our company has substantial proprietary knowledge, which is difficult to document in writing and blue prints that could be } \\
\text { leaked when dealing with } \\
\text { this particular supplier. } \\
\text { 2. Please indicate the extent to which the following activities were used in your supplier relationship }{ }^{c} \text { : } \\
\text { a. Technology sharing } \\
\text { b. Cost information sharing } \\
\text { 3. How extensive was the supplier's participation on your company's project team for this project? }{ }^{d} \\
\text { 4. How much direct cross-functional/intercompany communication (for example, engineer to engineer) took place between your } \\
\text { company and the supplier firm during the project? }{ }^{\mathrm{e}}\end{array}$ & .61 \\
\hline $\begin{array}{l}\text { Demand } \\
\text { uncertainty }^{\mathrm{f}}\end{array}$ & $\begin{array}{l}\text { 1. Demand and customer tastes are fairly easy to forecast. }{ }^{*} \\
\text { 2. Customers' product preferences change rapidly over time. }{ }^{\text {a }} \\
\text { 3. Customers tend to look for new products all the time. }{ }^{\text {a }} \\
\text { 4. It is hard to predict market changes. } \\
\text { 5. Industry sales volume for the end product is predictable. }{ }^{*}\end{array}$ & .78 \\
\hline
\end{tabular}


Table 6 (continued)

\begin{tabular}{|c|c|c|}
\hline Construct & Scale items & AVE \\
\hline & 6. Our company's sales volume for the end product is predictable. * & \\
\hline \multirow{5}{*}{$\begin{array}{c}\text { Technological } \\
\text { turbulence }\end{array}$} & 1. The technological sophistication of products in our industry is changing rapidly. ${ }^{\text {a }}$ & \multirow[t]{5}{*}{.75} \\
\hline & 2. A large number of new product ideas have been made possible through technological breakthroughs. ${ }^{\text {a }}$ & \\
\hline & 3. In our principal industry, the modes of production and service change often. & \\
\hline & 4. In our principal industry, the modes of production and service change in major ways as opposed to slowly evolving. & \\
\hline & 5. In our principal industry, it is difficult to forecast where the technology will be in the near future. & \\
\hline \multirow{5}{*}{$\begin{array}{l}\text { Competitive } \\
\text { intensity }\end{array}$} & 1. Our industry is characterized by aggressive competition. & \multirow[t]{5}{*}{.70} \\
\hline & 2. Many competitors operate in our industry. & \\
\hline & 3. It is hard to predict competitors' actions. ${ }^{\text {a }}$ & \\
\hline & 4. In our industry, there are very similar competing product and services. ${ }^{a}$ & \\
\hline & 5. New product (or service) introductions or modifications by competitors are frequent in our industry. & \\
\hline \multicolumn{3}{|c|}{ (*): Reverse coded items } \\
\hline \multicolumn{3}{|c|}{$\left({ }^{a}\right)$ : Items deleted during scale purification } \\
\hline \multicolumn{3}{|c|}{$\left({ }^{b}\right)$ : Based on a 7 point scale in which 1 indicates not very extensive, 7 very extensive } \\
\hline \multicolumn{3}{|c|}{$\left({ }^{c}\right)$ : Based on a 7 point scale in which 1 indicates no use, 7 extensive use } \\
\hline \multicolumn{3}{|c|}{$\left({ }^{d}\right)$ : Based on a 7 point scale in which 1 indicates no participation at all, and 7 very high participation } \\
\hline \multicolumn{3}{|c|}{$\left({ }^{\mathrm{e}}\right)$ : Based on a 7 point scale in which 1 indicates no such communication at all, and 7 very high degree of communication } \\
\hline \multicolumn{3}{|c|}{$\begin{array}{l}\left({ }^{\mathrm{f}}\right) \text { : The following items are based on the industry the company operates in (that is, the principal industry) that accounts for the largest } \% \text { of the company } \\
\text { sales }\end{array}$} \\
\hline
\end{tabular}

\section{References}

Ali, A. (1994). Pioneering versus incremental innovation: review and research propositions. Journal of Product Innovation Management, 11(1), 46-61.

Anderson, J. C., \& Gerbing, D. W. (1988). Structural equation modeling in practice: a review and recommended two-step approach. Psychological Bulletin, 103(3), 411-423.

Anderson, E., \& Weitz, B. (1992). The use of pledges to build and sustain commitment in distribution channels. Journal of Marketing Research, 29(1), 18-34.

Bagozzi, R. P., \& Edwards, J. R. (1998). A general approach for representing constructs in organizational research. Organizational Research Methods, 1, 45-87.

Bagozzi, R. P., \& Yi, Y. (2011). Specification, evaluation, and interpretation of structural equation models. Journal of the Academy of Marketing Science, 40(1), 8-34.

Baker, W. E., \& Sinkula, J. M. (2007). Does market orientation facilitate balanced innovation programs? An organizational learning perspective. Journal of Product Innovation Management, 24(4), 316-334.

Basmann, R. L. (1957). A generalized classical method of linear estimation of coefficients in a structural equation. Econometrica: Journal of the Econometric Society, 25(1), 77-83.

Bergen, M., Dutta, S., \& Walker Jr., O. C. (1992). Agency relationships in marketing: a review of the implications and applications of agency and related theories. Journal of Marketing, 3(July), 1-24.

Boeh, K. K., \& Beamish, P. W. (2012). Travel time and the liability of distance in foreign direct investment: Location choice and entry mode. Journal of International Business Studies, 43(5), 525-535.

Brehm, J. W. (1966). A theory of psychological reactance. New York: Academic Press.

Buvik, A., \& John, G. (2000). When does vertical coordination improve industrial purchasing relationships? Journal of Marketing, 64(4), 52-64.

Carson, S. J. (2007). When to give up control of outsourced new product development. Journal of Marketing, 71(1), 49-66.

Carson, S. J., \& John, G. (2013). A theoretical and empirical investigation of property rights sharing in outsourced research development and engineering relationships. Strategic Management Journal, 34(September), 1065-1085.

Celly, K. S., \& Frazier, G. L. (1996). Outcome-based and behavior-based coordination efforts in channel relationships. Journal of Marketing Research, 33(3), 200-210.

Chen, Y., Ganesan, S., \& Liu, Y. (2009). Does a firm's product-recall strategy affect its financial value? An examination of strategic alternatives during product-harm crises. Journal of Marketing, 73(6), 214-226.

Choudhury, V., \& Sabherwal, R. (2003). Portfolios of control in outsourced software development projects. Information Systems Research, 14(3), 291-314.

Cooper, R. G., \& Kleinschmidt, E. J. (1995). Benchmarking the firm's critical success factors in new product development. Journal of Product Innovation Management, 12(5), 374-391.

Cui, A. S. (2013). Portfolio dynamics and Alliance termination: the contingent role of resource dissimilarity. Journal of Marketing, 77(3), 15-32.

Danese, P., \& Filippini, R. (2013). Direct and mediated effects of product modularity on development time and product performance. IEEE Transactions on Engineering Management, 60, 260-271.

Deci, E. L., Koestner, R., \& Ryan, R. M. (1999). A meta-analytic review of experiments examining the effects of extrinsic rewards on intrinsic motivation. Psychological Bulletin, 125(6), 627-668.

Eisenhardt, K. M. (1985). Control: organizational and economic approaches. Management Science, 31(2), 134-149.

Ethiraj, S. K., \& Levinthal, D. (2004). Modularity and innovation in complex systems. Management Science, 50(2), 159-173.

Evans, M. G. (1985). A Monte Carlo study of the effects of correlated method variance in moderated multiple regression analysis. Organizational Behavior and Human Decision Processes, 36, 305-323.

Fang, E. (2011). The effect of strategic alliance knowledge complementarity on new product innovativeness in China. Organization Science, 22(1), 158-172.

Fornell, C., \& Larcker, D. F. (1981). Evaluating structural equation models with unobservable variables and measurement error. Journal of Marketing Research, 18(February), 39-50. 
Frazier, G. L., Maltz, E., Antia, K. D., \& Rindfleisch, A. (2009). Distributor sharing of strategic information with suppliers. Journal of Marketing, 73(4), 31-43.

Ganesan, S. (1994). Determinants of long-term orientation in buyer-seller relationships. Journal of Marketing, 58(2), 1-19.

Gao, G. Y., Xie, E., \& Zhou, K. Z. (2015). How does technological diversity in supplier network drive buyer innovation? Relational process and contingencies. Journal of Operations Management, 36, 165-177.

Geyskens, I., Steenkamp, J. B. E. M., \& Kumar, N. (2006). Make, buy, or ally: a transaction cost theory meta-analysis. Academy of Management Journal, 49(3), 519-543.

Ghosh, M., Dutta, S., \& Stremersch, S. (2006). Customizing complex products: when should the vendor take control? Journal of Marketing Research, 43(4), 664-679.

Grant, R. M. (1996). Toward a knowledge-based theory of the firm. Strategic Management Journal., 17, 109-122.

Grant, R. M., \& Baden-Fuller, C. (2004). A knowledge accessing theory of strategic alliances. Journal of Management Studies, 41(1), 61-84.

Grewal, R., Chakravarty, A., \& Saini, A. (2010). Governance mechanisms in business-to-business electronic markets. Journal of Marketing, 74(4), 45-62.

Griffith, D. A., Harmancioglu, N., \& Droge, C. (2009). Governance decisions for the offshore outsourcing of new product development in technology intensive markets. Journal of World Business, 44(3), 217-224.

Griffith, D. A., Hoppner, J. J., Lee, H. S., \& Schoenherr, T. (2017). The influence of the structure of interdependence on the response to inequity in buyer-supplier relationships. Journal of Marketing Research, 54(1), 124-137.

Gulati, R., \& Gargiulo, M. (1999). Where do interorganizational networks come from? American Journal of Sociology, 104(5), 1439-1493.

Heide, J. B., \& John, G. (1990). Alliances in industrial purchasing: the determinants of joint action in buyer-supplier relationships. Journal of Marketing Research, 27(1), 24-36.

Heide, J. B., \& Wathne, K. H. (2006). Friends, businesspeople, and relationship roles: a conceptual framework and a research agenda. Journal of Marketing, 70(3), 90-103.

Heide, J. B., \& Weiss, A. M. (1995). Vendor consideration and switching behavior for buyers in high-technology markets. Journal of Marketing, 59(3), 30-43.

Heide, J. B., Wathne, K. H., \& Rokkan, A. I. (2007). Interfirm monitoring, social contracts, and relationship outcomes. Journal of Marketing Research, 44(3), 425-433.

Ho, H., \& Ganesan, S. (2013). Does knowledge base compatibility help or hurt knowledge sharing between suppliers in coopetition? The role of customer participation. Journal of Marketing, 77(6), 91-107.

Hoetker, G. (2006). Do modular products lead to modular organizations? Strategic Management Journal, 27(6), 501-518.

Holmes, M. (1995). The utilization of CAD/CAM technologies in the styling process at Chrysler. Address to Conference on Joining Information Infrastructures and Technology Management for Global Enterprises, University of Illinois, Champaign, IL, October 11.

Homburg, C., Theel, M., \& Hohenberg, S. (2020). Marketing excellence: nature, measurement, and investor valuations. Journal of Marketing, $84(4), 1-22$.

Houston, M. B., \& Johnson, S. A. (2000). Buyer-supplier contrasts versus joint ventures: determinants and consequences of transaction structure. Journal of Marketing Research, 37(1), 1-15.

Howard, M., \& Squire, B. (2007). Modularization and the impact on supply relationships. International Journal of Operations \& Production Management, 27(11), 1192-1212.

Jap, S. D., \& Ganesan, S. (2000). Control mechanisms and the relationship life cycle: implications for safeguarding specific investments and developing commitment. Journal of Marketing Research, 37(2), $227-245$.
Jasmand, C., Blazevic, V., \& de Ruyter, K. (2012). Generating sales while providing service: a study of customer service representatives' ambidextrous behavior. Journal of Marketing, 76, 20-37.

Jaworski, B. J. (1988). Toward a theory of marketing control: environmental context, control types and consequences. Journal of Marketing, 52(3), 23-54.

John, G., Weiss, A. M., \& Dutta, S. (1999). Marketing in technologyintensive markets: toward a conceptual framework. Journal of Marketing, 63, 78-92.

Kalnins, A. (2018). Multicollinearity: how common factors cause type 1 errors in multivariate regression. Strategic Management Journal, 39(8), 2362-2385.

Katz, M. L., \& Shapiro, C. (1994). Systems competition and network effects. Journal of Economic Perspectives, 8(2), 93-115.

Kim, S. K., Stump, R. L., \& Oh, C. (2009). Driving forces of coordination costs in distributor-supplier relationships: toward a middle-range theory. Journal of the Academy of Marketing Science, 37(4), 384 399.

Kim, S. K., McFarland, R. G., Kwon, S., Son, S., \& Griffith, D. A. (2011). Understanding governance decisions in a partially integrated channel: a contingent alignment framework. Journal of Marketing Research, 48(3), 603-616.

Kirmani, A., \& Rao, A. R. (2000). No pain, no gain: a critical review of the literature on signaling unobservable product quality. Journal of Marketing, 64(2), 66-79.

Korschun, D., Bhattacharya, C. B., \& Swain, S. D. (2014). Corporate social responsibility, customer orientation, and the job performance of frontline employees. Journal of Marketing, 78(3), 20-37.

Lawless, M. W., \& Price, L. L. (1992). An agency perspective on new technology champions. Organization Science, 3(3), 342-355.

Lindell, M. K., \& Whitney, D. J. (2001). Accounting for common method variance in cross-sectional research designs. Journal of Applied Psychology, 86(1), 114-121.

Little, T. D., Cunningham, W. A., Shahar, G., \& Widaman, K. F. (2002). To parcel or not to parcel: exploring the question, weighing the merits. Structural Equation Modeling, 9(2), 151-173.

Luo, Y. (2002). Contract, cooperation, and performance in international joint ventures. Strategic Management Journal, 23(10), 903-919.

Malhotra, N. K., Kim, S. S., \& Patil, A. (2006). Common method variance in IS research: a comparison of alternative approaches and a reanalysis of past research. Management Science, 52(12), 1865 1883.

Markham, S. K., \& Lee, H. (2013). Product development and management association's 2012 comparative performance assessment study. Journal of Product Innovation Management, 30(3), 408-429.

Mayer, K. J., \& Salomon, R. M. (2006). Capabilities, contractual hazards, and governance: integrating resource-based and transaction cost perspectives. The Academy of Management Journal, 49(5), 942-959.

Moeen, M., \& Mitchell, W. (2020). How do pre-entrants to the industry incubation stage choose between alliances and acquisitions for technical capabilities and specialized complementary assets?. Strategic Management Journal, 1-40.

Mooi, E. A., \& Ghosh, M. (2010). Contract specificity and its performance implications. Journal of Marketing, 74(2), 105-120.

Morgan, R. M., \& Hunt, S. D. (1994). The commitment-trust theory of relationship marketing. Journal of Marketing, 58(3), 20-38.

Muller, D., Judd, C. M., \& Yzerbyt, V. Y. (2005). When moderation is mediated and mediation is moderated. Journal of Personality and Social Psychology, 89(6), 852-863.

Myers, M. B., Calantone, R. J., Page Jr., T. J., \& Taylor, C. R. (2000). Academic insights: an application of multiple-group causal models in assessing cross-cultural measurement equivalence. Journal of International Marketing, 8(4), 108-121.

Noordhoff, C. S., Kyriakopoulos, K., Moorman, C., Pauwels, P., \& Dellaert, B. G. (2011). The bright side and dark side of embedded 
ties in business-to-business innovation. Journal of Marketing, 75(5), $34-52$.

Oliver, R. L., \& Anderson, E. (1994). An empirical test of the consequences of behavior- and outcome-based sales control systems. Journal of Marketing, 58(4), 53-67.

Orton, J. D., \& Weick, K. E. (1990). Loosely coupled systems: a reconceptualization. Academy of Management Review, 15(2), 203-233.

Ouchi, W. G. (1979). A conceptual framework for the design of organizational control mechanisms. Management Science, 25(9), 833848.

Özturan, P., Özsomer, A., \& Pieters, R. (2014). The role of market orientation in advertising spending during economic collapse: the case of Turkey in 2001. Journal of Marketing Research, 51(2), 139-152.

Palmatier, R. W., Dant, R. P., \& Grewal, D. (2007). A comparative longitudinal analysis of theoretical perspectives of interorganizational relationship performance. Journal of Marketing, 71, 172-194.

Papies, D., Ebbes, P., \& Van Heerde, H. J. (2017). Addressing endogeneity in marketing models. In Advanced methods for modeling markets (pp. 581-627). Springer, Cham.

Parmigiani, A., \& Mitchell, W. (2009). Complementarity, capabilities, and the boundaries of the firm: the impact of within-firm and interfirm expertise on concurrent sourcing of complementary components. Strategic Management Journal, 30(10), 1065-1090.

Perrow, C. (1986). Complex organizations: A critical essay. U.S.A: McGraw-Hill Companies, Incorporated.

Petersen, K. J., Handfield, R. B., \& Ragatz, G. L. (2003). A model of supplier integration into new product development. Journal of Product Innovation Management, 20(4), 284-299.

Podsakoff, P. M., MacKenzie, S. B., Lee, J.-Y., \& Podsakoff, N. P. (2012). Sources of method bias in social science research and recommendations on how to control it. Annual Review of Psychology, 63, 539-569.

Preacher, K. J., Rucker, D. D., \& Hayes, A. F. (2007). Addressing moderated mediation hypotheses: theory, methods, and prescriptions. Multivariate Behavioral Research, 42(1), 185-227.

Raassens, N., Wuyts, S., \& Geyskens, I. (2012). The market valuation of outsourcing new product development. Journal of Marketing Research, 49(5), 682-695.

Rokkan, A. I., Heide, J. B., \& Wathne, K. H. (2003). Specific investments in marketing relationships: expropriation and bonding effects. Journal of Marketing Research, 40(2), 210-224.

Ross Jr., W. T., \& Robertson, D. C. (2007). Compound relationships between firms. Journal of Marketing, 71(3), 108-123.

Rowley, T., Behrens, D., \& Krackhardt, D. (2000). Redundant governance structures: An analysis of structural and relational embeddedness in the steel and semiconductor industries. Strategic Management Journal, 21(3), 369-386.

Sanchez, R. (1995). Strategic flexibility in product competition. Strategic Management Journal, 16(Special Issue), 135-159.

Sanchez, R. (1999). Modular architectures in the marketing process. Journal of Marketing, 63, 92-111.

Sargan, J. D. (1958). The estimation of economic relationships using instrumental variables. Econometrica, 26(3), 393-415.

Schilling, M. A. (2000). Toward a general modular systems theory and its application to interfirm product modularity. Academy of Management Review, 25(2), 312-334.

Schmitz, C., Lee, Y.-C., \& Lilien, G. L. (2014). Cross-selling performance in complex selling contexts: an examination of supervisoryand compensation-based controls. Journal of Marketing, 78, 1-19.

Siemsen, E., Roth, A., \& Oliveira, P. (2010). Common method bias in regression models with linear, quadratic, and interaction effects. Organizational Research Methods, 13(3), 456-476.

Sivadas, E., \& Dwyer, F. R. (2000). An examination of organizational factors influencing new product success in internal and alliancebased processes. Journal of Marketing, 64(1), 31-49.
Sislain, E., \& Satir, A. (2000). Strategic sourcing: a framework and a case study. Journal of Supply Chain Management, 36(Summer), 4-11.

Stock, J. H., \& Watson, M. W. (2011). Dynamic factor models. In Oxford handbook of economic forecasting. USA: Oxford University Press, 35-59.

Stremersch, S., Weiss, A. M., Dellaert, B. G. C., \& Frambach, R. T. (2003). Buying modular systems in technology-intensive markets. Journal of Marketing Research, 40(3), 335-350.

Stump, R. L., \& Heide, J. B. (1996). Controlling supplier opportunism in industrial relationships. Journal of Marketing Research, 33(4), 431441.

Teece, D. J. (1986). Profiting from technological innovation: implications for integration, collaboration, licensing and public policy. Research Policy, 15(6), 285-305.

Tiwana, A. (2008). Do bridging ties complement strong ties? An empirical examination of alliance ambidexterity. Strategic Management Journal, 29(3), 251-272.

Tiwana, A., \& Keil, M. (2007). Does peripheral knowledge complement control? An empirical test in technology outsourcing alliances. Strategic Management Journal, 28(6), 623-634.

Utterback, J. M. (1994). Radical innovation and corporate regeneration. Research-Technology Management, 37(4), 10.

Uzzi, B. (1996). The sources and consequences of embeddedness for the economic performance of organizations: the network effect. American Sociological Review, 61(4), 674-698.

Wang, Q., Bradford, K., Xu, J., \& Weitz, B. (2008). Creativity in buyerseller relationships: the role of governance. International Journal of Research in Marketing, 25(2), 109-118.

Wathne, K. H., \& Heide, J. B. (2000). Opportunism in interfirm relationships, forms, outcomes, and solutions. Journal of Marketing, 64(4), $36-51$.

Wathne, K. H., \& Heide, J. B. (2004). Relationship governance in a supply chain network. Journal of Marketing, 68(1), 73-89.

Weiss, A. M., \& Heide, J. B. (1993). The nature of organizational search in high technology markets. Journal of Marketing Research, 30(2), 220-233.

West, J., \& Bogers, M. (2014). Leveraging external sources of innovation: a review of research on open innovation. Journal of Product Innovation Management, 31(4), 814-831.

Williamson, O. E. (1991). Comparative economic organization: the analysis of discrete structural alternatives. Administrative Science Quarterly, 36(June), 269-296.

Wilson, L. O., Weiss, A. M., \& John, G. (1990). Unbundling of industrial systems. Journal of Marketing Research, 27(2), 123-138.

Worren, N., Moore, K., \& Cardona, P. (2002). Modularity, strategic flexibility, and firm performance: a study of the home appliance industry. Strategic Management Journal, 23(12), 1123-1140.

Wu, Q., Luo, X., Slotegraaf, R. J., \& Aspara, J. (2015). Sleeping with competitors: the impact of NPD phases on stock market reactions to horizontal collaboration. Journal of the Academy of Marketing Science, 43(4), 490-511.

Wuyts, S. (2007). Extra-role behavior in buyer-supplier relationships. International Journal of Research in Marketing, 24(4), 301-311.

Wuyts, S., \& Geyskens, I. (2005). The formation of buyer-supplier relationships: detailed contract drafting and close partner selection. Journal of Marketing, 69(4), 103-117.

Wuyts, S., Dutta, S., \& Stremersch, S. (2004). Portfolios of interfirm agreements in technology-intensive markets: consequences for innovation and profitability. Journal of Marketing, 68(2), 88-100.

Wuyts, S., Colombo, M. G., Dutta, S., \& Nooteboom, B. (2005). Empirical tests of optimal cognitive distance. Journal of Economic Behavior \& Organization, 58, 277-302.

Zaheer, S. (1995). Overcoming the liability of foreignness. Academy of Management Journal, 38(2), 341-363. 
Zhao, X., Lynch Jr., J. G., \& Chen, Q. (2010). Reconsidering baron and Kenny: myths and truths about mediation analysis. Journal of Consumer Research, 37(August), 197-206.

Zhou, K. Z., Yim, C. K., \& Tse, D. K. (2005). The effects of strategic orientations on technology- and market-based breakthrough innovations. Journal of Marketing, 69(2), 42-60.

Zorn, M. L., DeGhetto, K., Ketchen Jr., D. J., \& Combs, J. G. (2020). The impact of hiring directors' choice-supportive bias and escalation of commitment on CEO compensation and dismissal following poor performance: a multimethod study. Strategic Management Journal, 41(2), 308-339.

Publisher's note Springer Nature remains neutral with regard to jurisdictional claims in published maps and institutional affiliations. 